\title{
PAI-1 derived from cancer-associated fibroblasts in esophageal squamous cell carcinoma promotes the invasion of cancer cells and the migration of macrophages
}

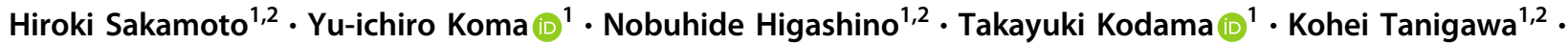 \\ Masaki Shimizu ${ }^{1,2} \cdot$ Masataka Fujikawa $^{1,2} \cdot$ Mari Nishio $^{1} \cdot$ Manabu Shigeoka $^{1} \cdot$ Yoshihiro Kakeji $^{2} \cdot$ \\ Hiroshi Yokozaki iD ${ }^{1}$
}

Received: 18 May 2020 / Revised: 10 November 2020 / Accepted: 11 November 2020 / Published online: 12 December 2020

(c) The Author(s) 2020. This article is published with open access

\begin{abstract}
Cancer-associated fibroblasts (CAFs) contribute to the progression of various cancers. Previously, we reported the significance of CAFs in esophageal squamous cell carcinoma (ESCC); however, the functions of CAFs in the ESCC microenvironment remain unknown. To investigate CAFs' function, we established an indirect coculture assay between human bone marrow-derived mesenchymal stem cells (MSCs) and ESCC cells. Cocultured MSCs expressed more fibroblast activation protein, one of the markers of CAFs, compared with monocultured MSCs. Therefore, we defined cocultured MSCs as CAF-like cells. To identify molecules associated with the ESCC progression in CAFs, we conducted a cDNA microarray analysis on monocultured MSCs and CAF-like cells to compare their gene expression profiles. We found that SERPINE1, which encodes plasminogen activator inhibitor-1 (PAI-1), was more abundant in CAF-like cells than in monocultured MSCs, and the PAI-1 derived from CAF-like cells induced the abilities of migration and invasion in both ESCC cells and macrophages by the Akt and Erk1/2 signaling pathways via the low-density lipoprotein receptor-related protein 1 (LRP1), which is a PAI-1 receptor. Based on immunohistochemistry assays of ESCC tissues, higher expression levels of PAI-1 and LRP1 were correlated with poor prognosis in ESCC patients. These results suggest that the PAI-1/LRP1 axis contributes to the progression of ESCC, making it a potential target for ESCC therapy.
\end{abstract}

\section{Introduction}

Globally, esophageal cancer is the seventh most common cancer and the sixth cause of cancer-related deaths. Esophageal cancer consists of two main histological types, including esophageal squamous cell carcinoma (ESCC) and esophageal adenocarcinoma. ESCC is the predominant

Supplementary information The online version of this article (https:// doi.org/10.1038/s41374-020-00512-2) contains supplementary material, which is available to authorized users.

Yu-ichiro Koma

koma069601119@gmail.com

1 Division of Pathology, Department of Pathology, Kobe University Graduate School of Medicine, 7-5-1 Kusunoki-cho, Chuo-ku, Kobe 650-0017, Japan

2 Division of Gastro-intestinal Surgery, Department of Surgery, Kobe University Graduate School of Medicine, 7-5-2 Kusunokicho, Chuo-ku, Kobe 650-0017, Japan histological type in east Asia, eastern and southern Africa, and southern Europe [1, 2]. Important risk factors for ESCC development are alcohol use, smoking, achalasia, race, and a high-starch diet, but the detailed mechanism remains unclear [3].

The tumor microenvironment (TME) can foster tumor progression. The TME includes various stromal cells, such as cancer-associated fibroblasts (CAFs), tumorassociated macrophages (TAMs), and other nonmalignant cells; and extracellular components (cytokines, growth factors, extracellular matrix, etc.) [4]. CAFs play key roles in tumor progression by mediating the activation of tumor proliferation, migration, and invasion, as well as the induction of angiogenesis, the stimulation of metastasis, and more [5, 6]. CAFs potentially originate from bone marrow-derived mesenchymal stem cells (MSCs), resident fibroblasts, endothelial cells, adipocytes, and epithelial cells [7]. The heterogeneous origin of CAFs accounts for their broad range of characteristics and their various molecular markers [8]. Alpha-smooth muscle 
actin ( $\alpha$ SMA) and fibroblast activation protein (FAP) are representative cellular markers of CAFs, and their elevated expressions are associated with poorer prognosis in several cancers $[9,10]$. Moreover, recent studies indicate that CAFs indirectly contribute to tumor progression by interacting with other stromal components of the TME such as TAMs [11, 12].

In a previous study, we characterized the mechanisms of tumor-promoting ability and immunosuppressive phenotype of CAFs in ESCC [13]. We observed that higher expression levels of $\alpha$ SMA and FAP in the tumor stroma were significantly associated with increasing depth of tumor invasion and lymph node metastasis, advanced pathological stage, and poorer prognosis in patients with ESCC. In addition, we performed a coculture assay between MSCs and ESCC cells and found an increase of FAP expression in the cocultured MSCs. These FAPpositive MSCs, which we defined as CAF-like cells, promoted the migrative abilities of both ESCC cells and macrophages by secreting C-C motif chemokine 2 (CCL2) and interleukin-6 (IL6) and induced the M2 polarization of macrophages. However, the interactions among CAFs, M2polarized macrophages (so-called TAMs), and ESCC cells have not been clarified in detail.

To explore the mechanisms by which CAFs enhance ESCC progression, we established CAF-like cells by coculturing MSCs with ESCC cells in vitro. We then compared the gene expression profiles between monocultured MSCs and CAF-like cells by cDNA microarray analysis and characterized the effects of CAF-like cells to ESCC cells and macrophages. Moreover, we identified possible key players underlying the tumorpromoting effects of CAF-like cells in the ESCC microenvironment that may be used as potential targets for ESCC therapy.

\section{Materials and methods}

\section{Cell lines and cell cultures}

Three human ESCC cell lines, TE-series ESCC cells (TE-8, TE-9, and TE-15 cells), were purchased from RIKEN BioResource Center (Tsukuba, Japan) and were cultured in RPMI-1640 (FUJIFILM Wako Pure Chemical, Osaka, Japan) containing 10\% FBS (Sigma-Aldrich, St. Louis, MO, USA) and 1\% antibiotic-antimycotic (Invitrogen, Carlsbad, CA, USA) [14]. The human MSCs (ATCC ${ }^{\circledR}$ PCS-500-012 ${ }^{\mathrm{TM}}$ ) were purchased from the American Type Culture Collection (Manassas, VA, USA) and were cultured in DMEM with low-glucose (FUJIFILM Wako Pure Chemical) containing $10 \%$ FBS and $1 \%$ antibioticantimycotic [13].

\section{Preparation of CAF-like cells and macrophages}

The method for the establishment of CAF-like cells was described in a previous report [13]. In brief, MSCs $\left(5 \times 10^{4}\right.$ cells) were seeded in the lower chamber of a 6 -well plate and cocultured with ESCC cells $\left(1.5 \times 10^{5}\right.$ cells $)$ in the upper chamber $(0.4-\mu \mathrm{m}$ pore size insert; BD Falcon, Lincoln Park, NY, USA) for 7 days. The media and the upper chamber with ESCC cells were changed 4 days after coculturing. As a control, MSCs were seeded without ESCC cells.

We induced macrophages from $\mathrm{CD} 14^{+}$peripheral blood monocytes (PBMos) as previously described [15, 16]. In brief, PBMos were purified from peripheral blood mononuclear cells by positive selection using an autoMACS ${ }^{\circledR}$ Pro Separator (Miltenyi Biotec, Bergisch Gladbach, Germany). Then, PBMos $\left(5 \times 10^{5}\right.$ cells $)$ in the 6 -well plate were cultured with macrophage-colony stimulating factor (M-CSF; $25 \mathrm{ng} / \mathrm{ml}$; R\&D Systems, Minneapolis, MN, USA) for 6 days to induce macrophages.

\section{CDNA microarray analysis}

The extraction of total RNA from MSCs or CAF-like cells was performed by the RNeasy Mini Kit (Qiagen, Hilden, Germany). We conducted cDNA microarray analysis using the 3D-Gene ${ }^{\circledR}$ Human Oligo chip 25k (Toray Industries, Tokyo, Japan). Microarray slides were scanned using the 3D-Gene ${ }^{\circledR}$ Scanner (Toray Industries) and processed using the 3D-Gene ${ }^{\circledR}$ Extraction software (Toray Industries). We have deposited these data in the Gene Expression Omnibus database (GSE143138).

\section{Reverse Transcription-PCR (RT-PCR) and quantitative RT-PCR (qRT-PCR)}

The extraction of total RNA from each cell was performed by the RNeasy Mini Kit (Qiagen). We performed RT-PCR and qRT-PCR as previously reported [13]. RT-PCR products of LRPI and GAPDH (control) were separated by electrophoresis in agarose gel $(2 \%)$. We conducted qRTPCR amplifications of FAP, SERPINE1, IL6, CCL2, CXCL12, CD163, MSR1, CD274, and ACTB (control) on the StepOne ${ }^{\mathrm{TM}}$ Real-Time PCR System (Thermo Fisher Scientific, Waltham, MA, USA) using Taqman ${ }^{\circledR}$ Gene Expression Master Mix (Thermo Fisher Scientific). Primers and probes are listed in Table S1.

\section{Western blotting}

Methods to extract cellular proteins and western blotting are described elsewhere [13]. In brief, cells were lysed on ice with a RIPA Lysis and Extraction Buffer (Thermo 
Fig. 1 PAI-1 expression and secretion were induced in CAF-like cells. a Mesenchymal stem cells (MSCs) were cocultured with esophageal squamous cell carcinoma (ESCC) cell lines TE-8, TE-9, or TE-15 cells (herein defined as CAF-like cells, CAF8, CAF9, or CAF15, respectively) for 7 days. b Gene expression heatmap of monocultured MSCs and three CAF-like cells sorted in the descending order of upregulated gene expression levels in CAF9 cells. Phylogenetic tree on top of the heatmap compares gene expression patterns of the different cell types. c Levels of SERPINE1 mRNA in MSC,

CAF-like cells, and ESCC cells were determined by quantitative RT-PCR and normalized relative to ACTB ( $\beta$-actin).

d Concentrations of PAI- 1 in the supernatants of MSCs, CAF-like cells, and ESCC cells measured by ELISA. For (c) and (d), data represent the mean \pm SEM of triplicate wells for three independent experiments $(* p<0.05, * * * p<0.001)$
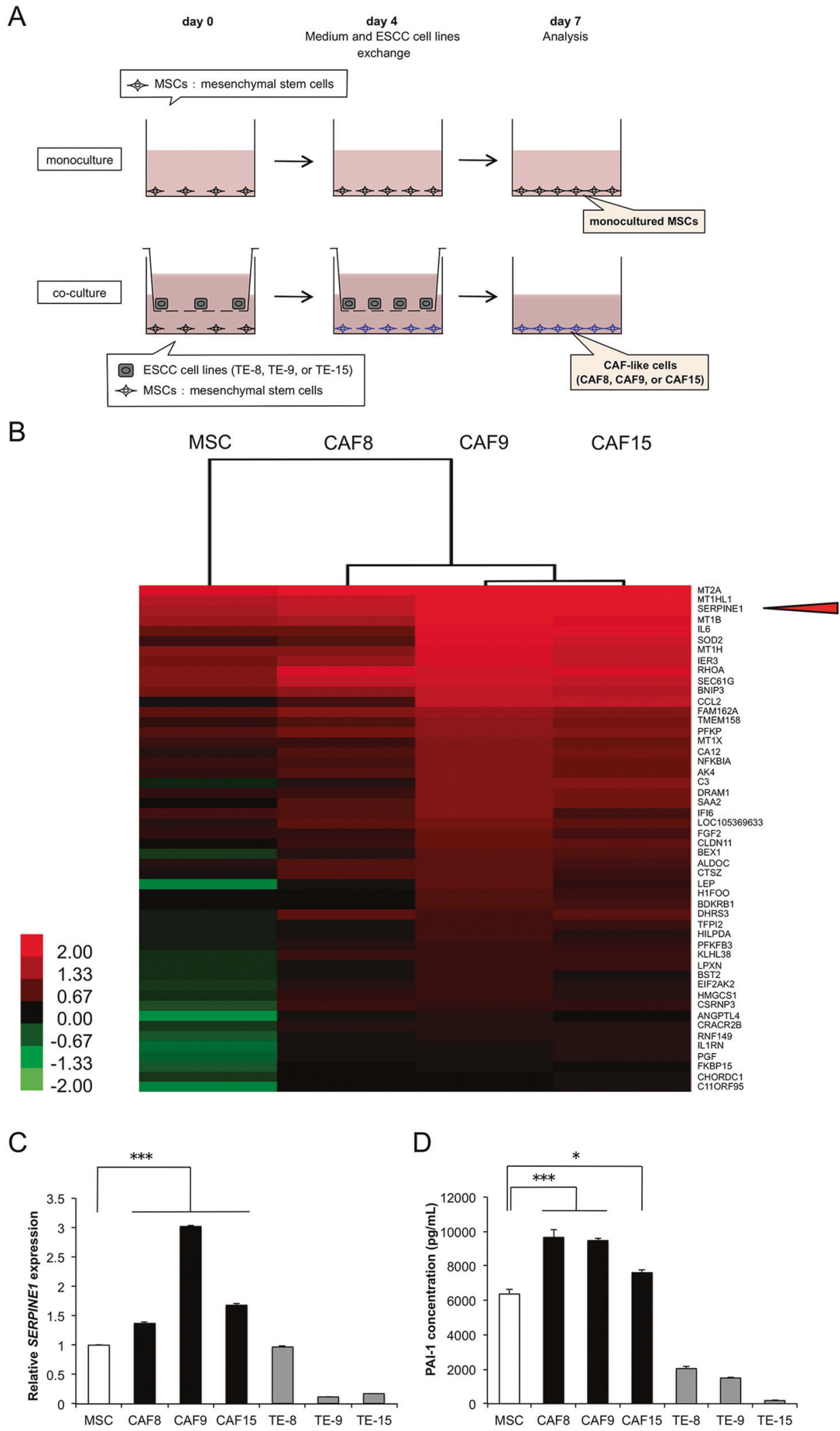

Fisher Scientific) containing 1\% protease inhibitor and $1 \%$ phosphatase inhibitor cocktail (Sigma-Aldrich). The resulting lysates were separated on $5-20 \%$ sodium dodecyl sulfate polyacrylamide gels and transferred to a membrane with an iBlot $^{\circledR}$ Gel Transfer Stack (Invitrogen). The membrane was blocked with 5\% skim milk and 
Table 1 Up-regulated genes coding secretory proteins in CAF-like cells compared to monocultured MSCs.

\begin{tabular}{|c|c|c|c|c|c|}
\hline \multirow[t]{3}{*}{ Gene accession } & \multirow[t]{3}{*}{ Gene symbol } & \multirow[t]{3}{*}{ Gene description } & \multicolumn{3}{|c|}{ Fold change } \\
\hline & & & \multicolumn{3}{|c|}{$\begin{array}{l}\text { (CAF-like cells/ } \\
\text { monocultured MSCs) }\end{array}$} \\
\hline & & & CAF8 & CAF9 & CAF15 \\
\hline NM_000602.4 & SERPINE1 & $\begin{array}{l}\text { serpin peptidase inhibitor, clade } E \text { (nexin, } \\
\text { plasminogen activator inhibitor type } 1) \text {, } \\
\text { member } 1\end{array}$ & 1.43 & 4.36 & 3.62 \\
\hline XM_011515390.1 & IL6 & interleukin 6 & 1.09 & 11.81 & 9.85 \\
\hline NM_002982.3 & CCL2 & $C$-C motif chemokine ligand 2 & 2.27 & 23.87 & 22.54 \\
\hline
\end{tabular}

then incubated with primary and secondary antibodies. The protein bands were detected with ImmunoStar Reagents (FUJIFILM Wako Pure Chemical). The lists of primary and secondary antibodies are presented in Table S2. Densitometric analysis of the bands obtained in western blotting was performed using the Wand (tracing) tool in the ImageJ software (version 1.52a; National Institutes of Health, Bethesda, MD, USA), and the levels of phospho-proteins were normalized to total protein levels.

\section{ELISA}

The culture media of monocultured MSCs, CAF-like cells, and ESCC cells were exchanged to serum-free DMEM. After $24 \mathrm{~h}$, the supernatants were collected and analyzed by Human Serpin E1/PAI-1 Quantikine ${ }^{\circledR}$ ELISA Kit (R\&D Systems) in accordance with the manufacturer's instructions. The optical densities of each well were read at 450 and $570 \mathrm{~nm}$ using a microplate reader (Infinite ${ }^{\circledR} 200$ PRO; Tecan, Männedorf, Switzerland). The PAI-1 concentration in each well was calculated from the absorbance values using a standard curve.

\section{Transwell migration assay and transwell invasion assay}

We performed the transwell migration assay and transwell invasion assay using an $8.0-\mu \mathrm{m}$ pore size insert (BD Falcon) and a BioCoat ${ }^{\mathrm{TM}}$ Matrigel $^{\circledR}$ Invasion Chamber (Corning, Tewksbury, MA, USA), respectively. To investigate the effects of the coculture, CAFlike cells $\left(5 \times 10^{4}\right.$ cells $)$ in serum-free media were seeded in the lower chambers. The effect of recombinant human PAI-1 (rhPAI-1; R\&D Systems) was investigated by addition to the lower chambers. ESCC cells $\left(1 \times 10^{5}\right.$ cells for transwell migration assay; $3 \times 10^{5}$ cells for transwell invasion assay) or macrophages $\left(1 \times 10^{5}\right.$ cells for transwell migration assay; $3 \times 10^{5}$ cells for transwell invasion assay) in the serum-free media were seeded in the upper inserts. After $24 \mathrm{~h}$ or $48 \mathrm{~h}$, the cells that migrated through the membranes were stained using Diff-Quik ${ }^{\circledR}$ (Sysmex, Kobe, Japan) and counted. In some experiments, ESCC cells or macrophages were treated with PI3K inhibitor LY294002 (Cell Signaling Technology, Beverly, MA, USA) or MEK1/2 inhibitor PD98059 (Cell Signaling Technology); CAF-like cells were treated with neutralizing antibody against human PAI-1 (AF1786; R\&D Systems) or normal goat IgG (AB-108-C; R\&D Systems) as the negative control.

\section{Wound healing assay}

ESCC cells (TE-8 and TE-9 cells; $2 \times 10^{5}$ cells) in RPMI-1640 (FUJIFILM Wako Pure Chemical) containing $10 \%$ FBS (Sigma-Aldrich) were seeded in a 24-well plate. After $24 \mathrm{~h}$, the confluent cell monolayer was wounded by mechanical scratching and exchanged into serum-free media with or without rhPAI-1 at $10 \mathrm{ng} / \mathrm{mL}$ (R\&D Systems). After another $24 \mathrm{~h}$, we observed cells migrating to the wound area and calculated the percent wound coverage using the Polygon selection tool in the ImageJ software (National Institutes of Health). We excluded TE-15 cells from the wound healing assay based on their status as nest-forming and nonconfluent cells.

\section{Knockdown of LRP1 by siRNA}

ESCC cells or macrophages were transfected with $20 \mathrm{nM}$ siRNA against human LRPI (siLRP1, sc-40101; Santa Cruz Biotechnology, Dallas, TX, USA) or $20 \mathrm{nM}$ negative control siRNA (siNC, S1C-001; Sigma-Aldrich) for $48 \mathrm{~h}$ using Lipofectamine $^{\circledR}$ RNAiMAX (Invitrogen) in accordance with the manufacturer's instructions. After transfection, the cells were used for in vitro experiments.

\section{Tissue samples}

A total of 69 surgically resected cases of human ESCC tissues at Kobe University Hospital (Kobe, Japan) from 2005 to 2010 were included in this study, as previously 
A

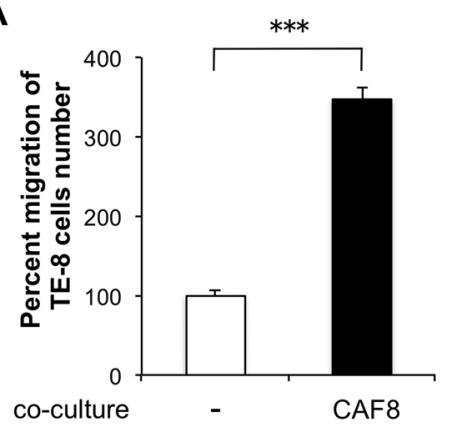

B

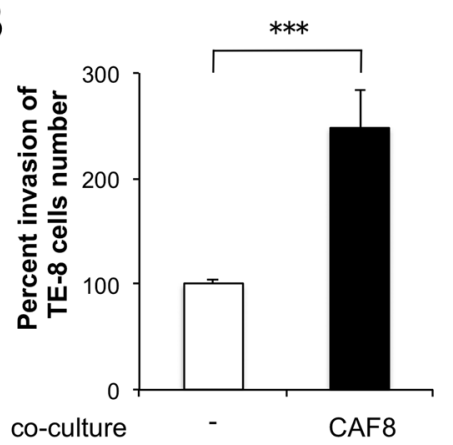

C

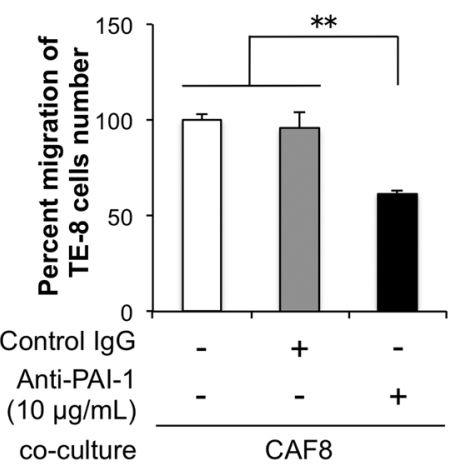

D

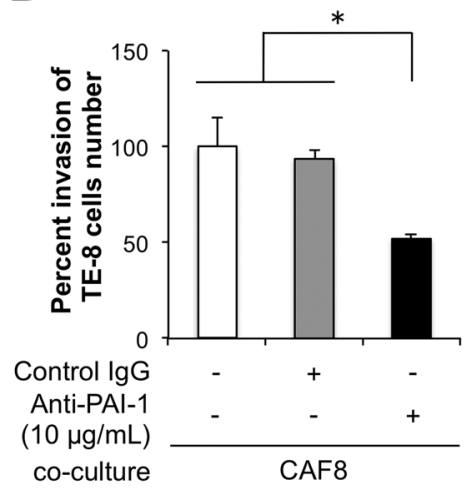

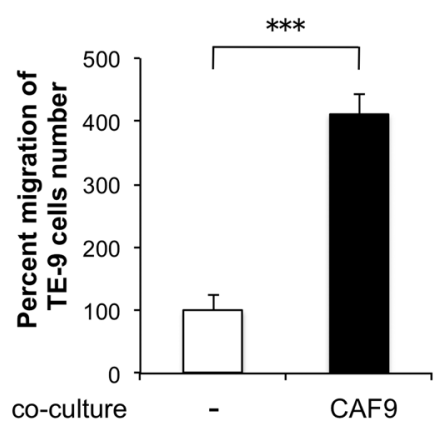
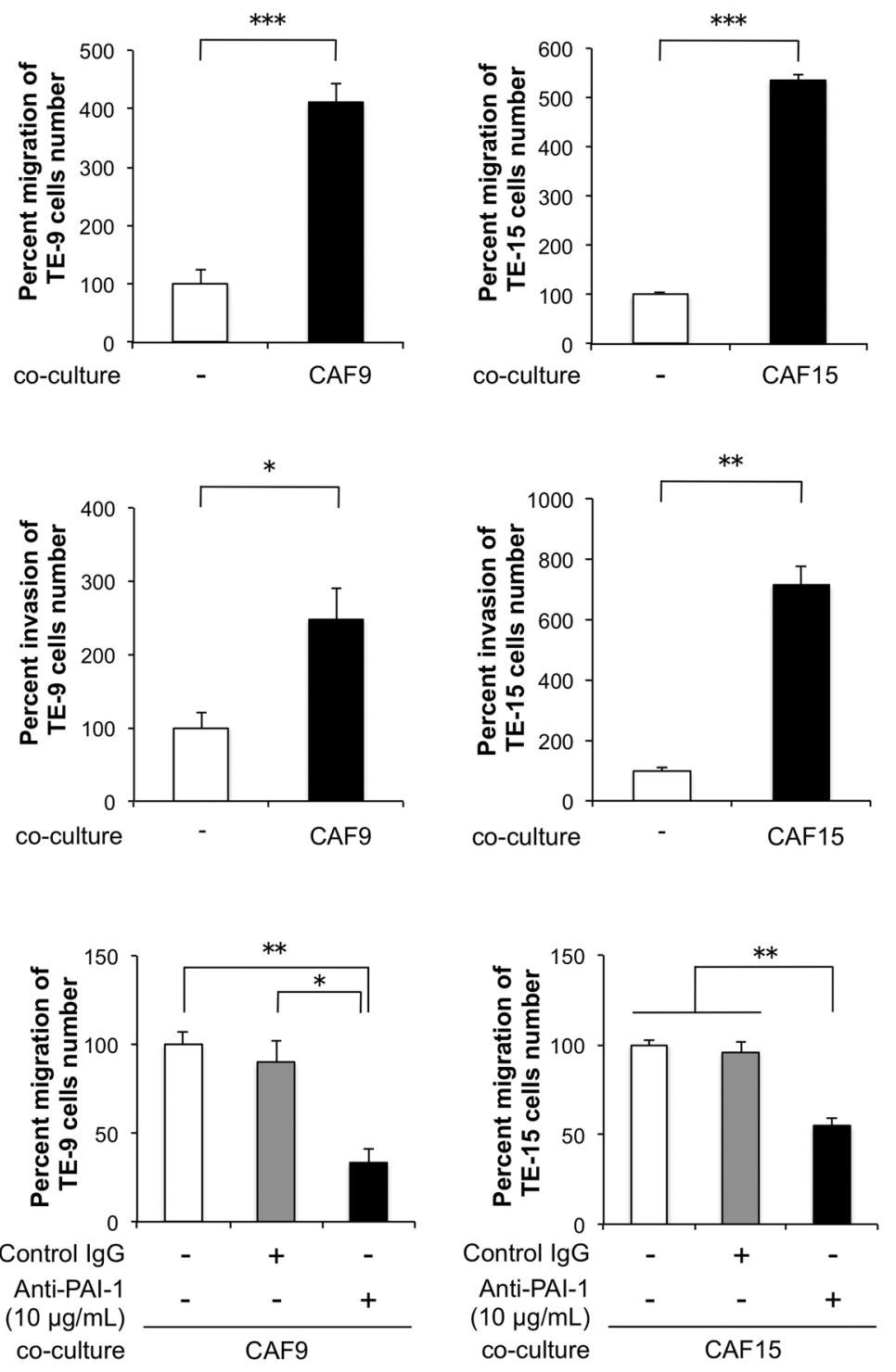

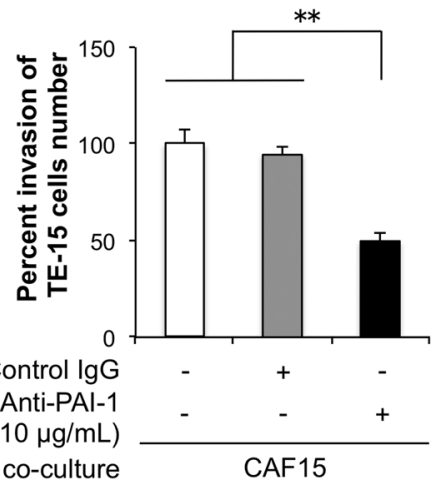

described [13, 17]. All patients had not received adjuvant chemotherapy or radiotherapy. Informed consent for the use of tissue samples and clinical data were obtained from all patients, and this study was approved by the Kobe University Institutional Review Board. Patient characteristics are presented in Table S3. 
Fig. 2 PAI-1 secreted by CAF-like cells promotes the migration and invasion of esophageal squamous cell carcinoma (ESCC) cells. a Transwell assay demonstrating the effects of CAF-like cells coculturing on the migration of TE-8, TE-9, and TE-15 cells. Migrating cells were counted in four randomly chosen fields. b Transwell assay demonstrating the effects of CAF-like cells coculturing on the invasion of TE-8, TE-9, and TE-15 cells. Invading cells were counted in four randomly chosen fields. c Transwell assay of the effects of PAI-1 neutralizing antibodies on the migration of TE-8, TE-9, and TE-15 cells cocultured with CAF-like cells. Normal goat IgG was the negative control for the PAI-1 antibody. $\mathbf{d}$ Transwell assay of the effects of PAI-1 neutralizing antibodies on the invasion of TE-8, TE-9, and TE15 cells cocultured with CAF-like cells. Normal goat IgG was the negative control for the PAI-1 antibody. For (a-d), data represent the mean \pm SEM of triplicate wells for three independent experiments $(* p<0.05, * * p<0.01, * * * p<0.001)$.

\section{Immunohistochemistry}

Immunohistochemistry was performed on $4-\mu \mathrm{m}$ tissue sections of paraffin-embedded specimens using EnVision Dual Link System-HRP (Agilent Technologies, Santa Clara, CA, USA) [13]. The list of primary antibodies is presented in Table S2. We used human placental tissue, which expressed both PAI-1 and LRP1 in villi, as a positive control and examined the condition of immunohistochemistry for these proteins (Fig. S1A). No immunoreactivity for normal rabbit IgG (sc-20271; Santa Cruz Biotechnology) was observed under the conditions used for the anti-PAI-1 and anti-LRP1 antibodies in human placental tissue (Fig. S1A) and human ESCC tissue (Fig. S1B, C). Qualitative scores for evaluating immunohistochemical staining intensities of PAI-1 in cancer stroma compared to those of vascular endothelial cells as positive control were as follows: negative to weak (low) and equal to strong (high). For LRP1 in cancer nests and cancer stroma were as follows: 0 (negative), 1 (weak), 2 (intermediate), and 3 (strong). Scores of 2 or 3 for LRP1 immunoreactivity were considered high. Two pathologists (YIK and HY) and one surgeon (HS), blinded to the patients' clinical data, performed immunoreactivity scoring. We evaluated the proportion of immunohistochemical $\alpha$ SMA- and FAP-positive areas of the stroma around the invasive front per $40 \times$ field ( $4 \times$ objective and $10 \times$ ocular) as low $(\leq 30 \%)$ and high ( $>30 \%$ ) [13]. The method for the evaluation of CD163 and CD204 labeling of macrophages was described in a previous report [17]. The mean number of macrophages per $200 \times$ field (20x objective and 10x ocular) was calculated.

\section{Immunofluorescence}

Double immunofluorescence was performed using anti-LRP1 and anti-CD204 antibodies in formalin-fixed paraffinembedded human ESCC tissue. The nuclei were stained with DAPI (DOJINDO LABORATORIES, Kumamoto, Japan). The lists of primary and secondary antibodies are presented in Table S2. All images were taken with a Zeiss LSM 700 laser- scanning microscope and analyzed using the LSM software ZEN 2009 (Carl Zeiss, Oberkochen, Germany).

\section{Statistical analysis}

Relationships between the immunohistochemical results and clinicopathological factors were analyzed by $\chi^{2}$-tests. Statistical significance in the in vitro assays were determined by two-tailed Student's $t$ test. A $p<0.05$ was considered statistically significant. Overall, disease-free and cause-specific survival (CSS) curves were estimated by the Kaplan-Meier method and compared using the log-rank test. Statistical analyses were carried out by SPSS Statistics version 22 (IBM, Chicago, IL, USA).

\section{Results}

\section{Expression of PAI-1 by MSCs and CAF-like cells}

The functions of CAFs in the ESCC microenvironment were assessed by an indirect coculture assay (Fig. 1a). The mRNA and protein expression levels of FAP were induced in cocultured MSCs with three TE-series ESCC cells, TE-8, TE-9, and TE15 cells (Fig. S2A, B). Hereafter, we define cocultured MSCs with TE-8, TE-9, and TE-15 cells as CAF-like cells, CAF8, CAF9, and CAF15 cells, respectively (Fig. 1a). We compared gene expression profiles of monocultured MSCs and CAF-like cells by cDNA microarray analysis. We identified 110 genes that were up-regulated (ratio >2.0) and 128 genes that were down-regulated (ratio $<0.5$ ) in CAF9 (Table S4). The heatmap shows the top 50 genes with high expression among the up-regulated genes in CAF9 (Fig. 1b). The phylogenetic analysis revealed that the gene expression patterns in CAF9 and CAF15 were the most similar among the different cell groups. The monocultured MSCs had an expression pattern different from the CAF-like cells.

In this study, we focused on serine protease inhibitor E1 (SERPINE1), one of the up-regulated, and highly expressed genes in CAF-like cells (Fig. 1b, Table 1). We confirmed the high expression levels of SERPINE1 mRNA as well as those of IL6, CCL2, and CXCL12 mRNA in CAF-like cells by qRT-PCR (Figs. 1c, S2C). The CAF-like cells secreted significantly higher concentrations of PAI-1 (which is encoded by SERPINE1) than monocultured MSCs (Fig. 1d). The results of the ELISA verified the secretion of PAI-1 from ESCC cells, especially from TE-8 and TE-9 cells (Fig. 1d).

\section{Neutralizing antibody against PAI-1 suppresses CAF- like cells-induced migration of ESCC cells}

Coculture with CAF-like cells, CAF8, CAF9, and CAF15 cells, significantly induced the migration and 
Fig. 3 PAI-1 promotes the migration and invasion of esophageal squamous cell carcinoma (ESCC) cells by activating Akt and Erk1/ 2 signaling pathways. a Levels of LRP1 mRNA in ESCC cells by RT-PCR. GAPDH used as internal control. b Expression of LRP1 in ESCC cells by western blotting. $\beta$-actin used as the loading control. c Transwell assay of the effects of recombinant human (rh) PAI-1 on the migration of TE-8, TE-9, and TE-15 cells. Migrating cells were counted in four randomly chosen fields. d Transwell assay of the effects of rhPAI- 1 on the invasion of TE-8, TE-9, and TE15 cells. Invading cells were counted in four randomly chosen fields. e Representative western blots of phosphorylated and total Akt and Erk1/2 in ESCC cells. TE-8, TE-9, and TE-15 cells in serum-free conditions were treated with $10 \mathrm{ng} / \mathrm{mL}$ rhPAI- 1 for $0,10,30$, and $60 \mathrm{~min}$. f Transwell migration assay of TE-8, TE-9, and TE- 15 cells with or without $10 \mathrm{ng} / \mathrm{mL}$ rhPAI-1 combined with an inhibitor against PI3K (LY294002, $10 \mu \mathrm{M}$ ) or MEK1/2 (PD98059, $10 \mu \mathrm{M}$ ). Migrating cells were counted in four randomly chosen fields. $\mathbf{g}$ Invasion assay of TE-8, TE-9, and TE- 15 cells with or without $10 \mathrm{ng} / \mathrm{mL}$ rhPAI-1 combined with an inhibitor against PI3K (LY294002, $10 \mu \mathrm{M}$ ) or MEK1/2 (PD98059, $10 \mu \mathrm{M}$ ). Invading cells were counted in four randomly chosen fields. For (c), (d), (f), and (g), data represent the mean \pm SEM of triplicate wells for three independent experiments $(* p<0.05$ $* * p<0.01, * * * p<0.001)$.
A
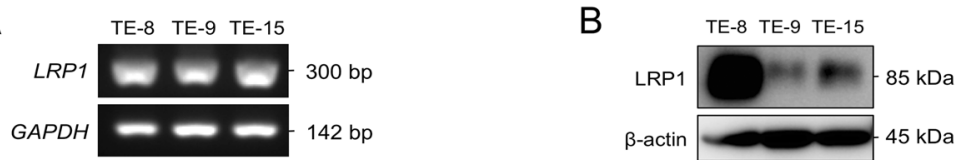

C
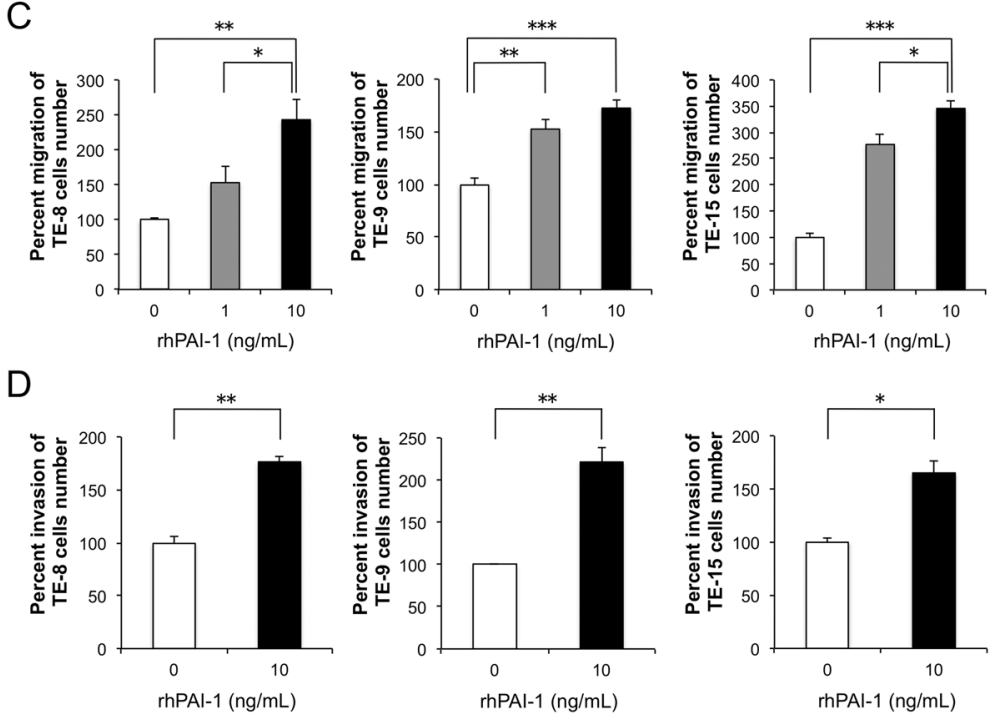

E

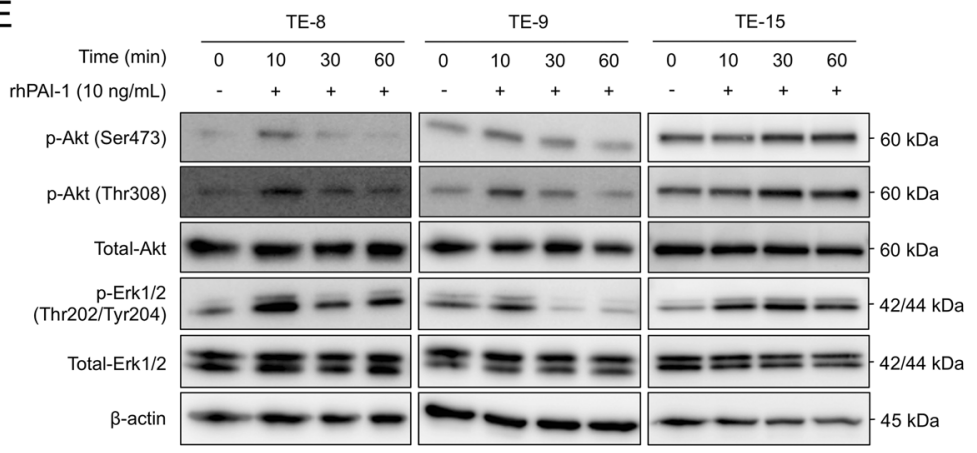

$\mathrm{F}$

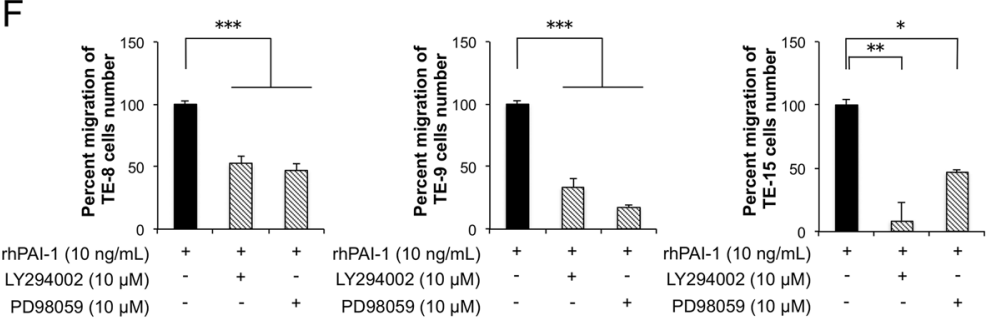

G

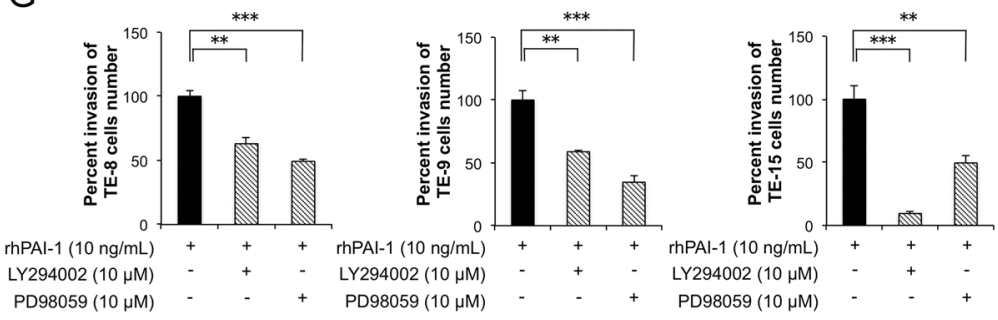

invasion abilities of three TE-series ESCC cells, TE-8, TE-9, and TE-15 cells, respectively (Fig. 2a, b). The addition of a neutralizing antibody against PAI-1 significantly suppressed the migration and invasion abilities of ESCC cells cocultured with CAF-like cells (Fig. 2c, d). 
A
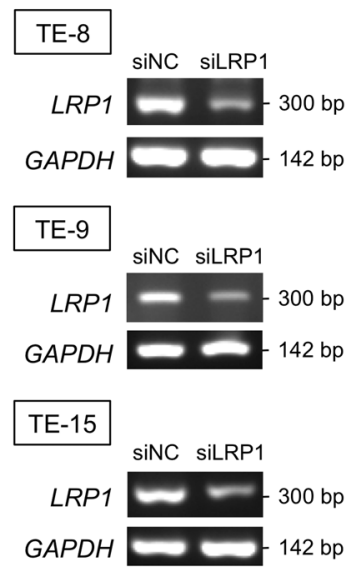

B

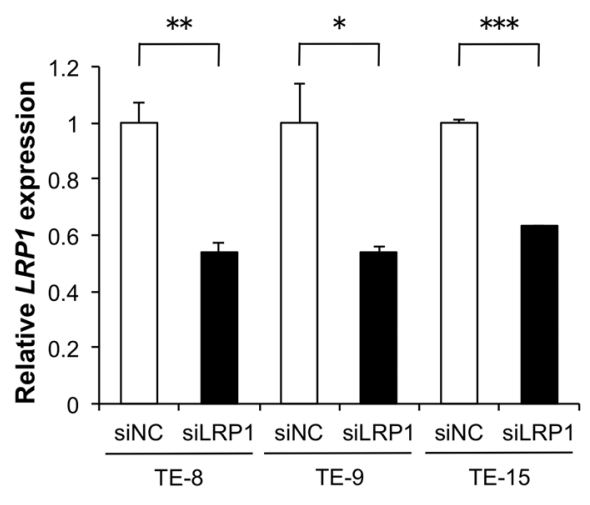

C
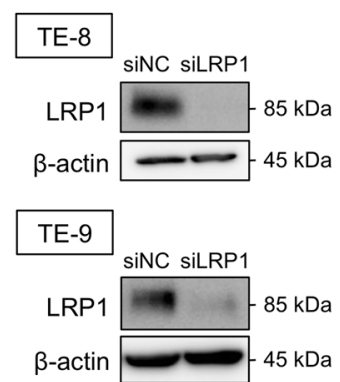

TE-15

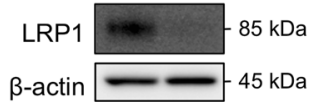

D
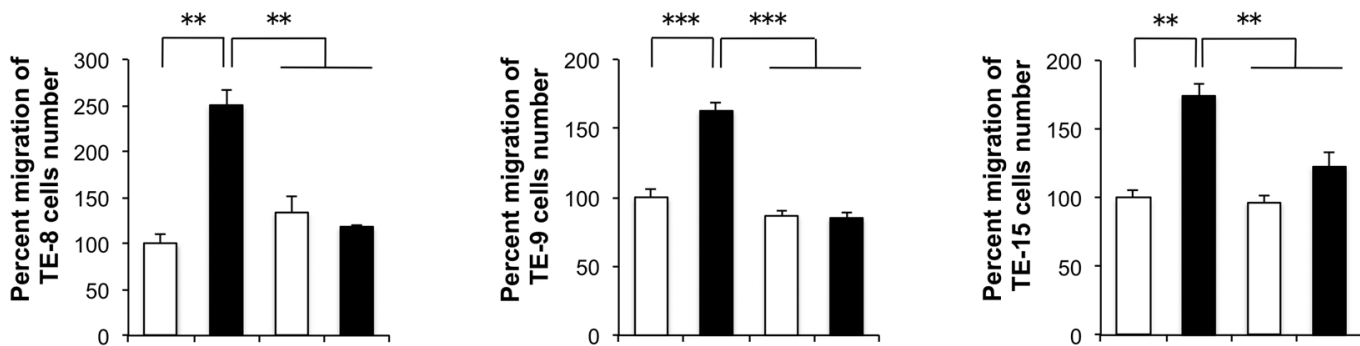

rhPAl-1 (10 ng/mL)

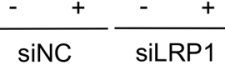

rhPAl-1 (10 ng/mL)

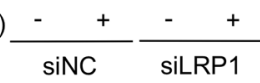

rhPAl-1 $(10 \mathrm{ng} / \mathrm{mL})$

E
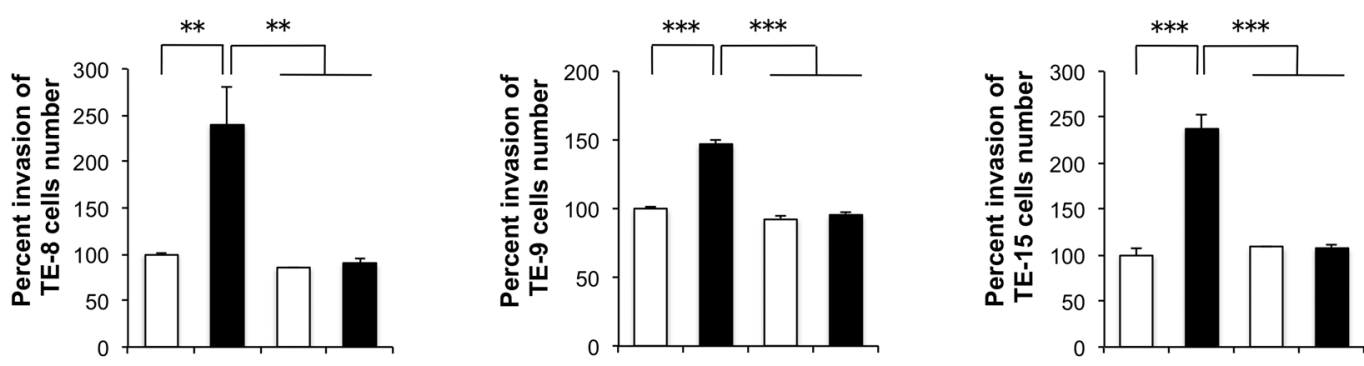

rhPAl-1 $(10 \mathrm{ng} / \mathrm{mL})$

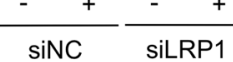

rhPAl-1 (10 ng/mL)

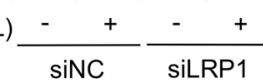

rhPAl-1 $(10 \mathrm{ng} / \mathrm{mL})$

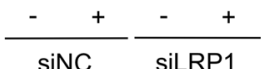

F

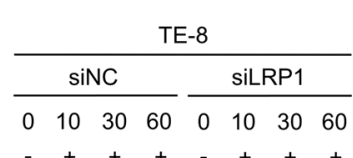

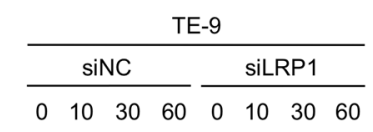

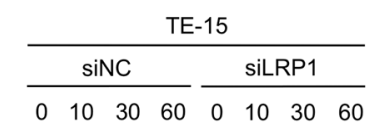
rhPAl-1 (10 ng/mL)
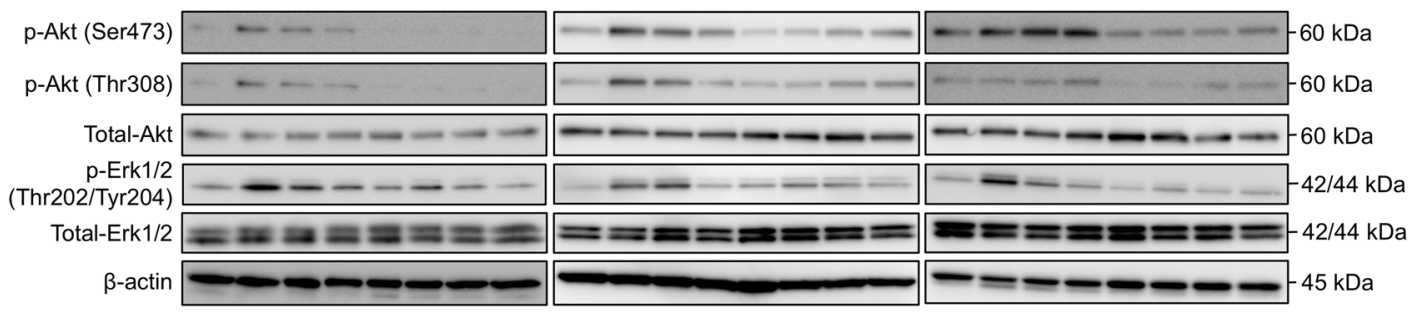
Fig. 4 Effects of LRP1 knockdown on the migration, invasion, and signaling of esophageal squamous cell carcinoma (ESCC) cells. a, b ESCC cells were transfected with $20 \mathrm{nM}$ siRNA targeting LRP1 (siLRP1). Negative control siRNA (siNC) was transfected into ESCC cells as negative control. LRP 1 knockdown was confirmed by (a) RT-PCR with GAPDH as the internal control, and by (b) quantitative RT-PCR with $L R P 1$ normalized to levels in respective samples and $A C T B$ ( $\beta$-actin) as the internal control. c Representative western blots of LRP1 knockdown in ESCC cells. $\beta$-actin used as the loading control. d Transwell assay of the effects of LRP1 knockdown on the migration of TE-8, TE-9, and TE-15 cells with or without $10 \mathrm{ng} / \mathrm{mL}$ rhPAI-1. Migrating cells were counted in four randomly chosen fields. e Transwell assay of the effects of LRP1 knockdown on the invasion of TE-8, TE-9, and TE-15 cells with or without $10 \mathrm{ng} / \mathrm{mL}$ rhPAI-1. Invading cells were counted in four randomly chosen fields. f Representative western blots of the total protein of LRP1-silenced ESCC cells using specific antibodies against Akt, p-Akt (Ser473), p-Akt (Thr308), Erk1/2, p-Erk1/2 (Thr202/Tyr204), and $\beta$-actin compared to the control. For $(\mathbf{b}),(\mathbf{d})$, and (e), data represent the mean \pm SEM of triplicate wells for three independent experiments $\left({ }^{*} p<0.05, *^{*} p<0.01\right.$, $* * * p<0.001)$

\section{PAI-1 induces the migration and invasion of ESCC cells by activating Akt and Erk1/2 signaling pathways}

We confirmed the expression of LRP1, a PAI-1 receptor, in three TE-series ESCC cells using RT-PCR and western blotting (Fig. 3a, b). To investigate the effects of PAI-1 on the phenotypes and the signaling pathways of ESCC cells, we applied rhPAI-1 to TE-8, TE-9, and TE-15 cells. RhPAI1 significantly promoted the migration and invasion abilities of ESCC cells (Fig. 3c, d). In addition, we confirmed that rhPAI- 1 promoted the migration of TE- 8 and TE- 9 cells by wound healing assay (Fig. S3). RhPAI-1 increased p-Akt (Ser473/Thr308) and p-Erk1/2 levels after 10 or $30 \mathrm{~min}$ of treatment (Figs. 3e, S4). The PI3K inhibitor LY294002 and MEK1/2 inhibitor PD98059 suppressed the induction of both migration and invasion in rhPAI-1-treated ESCC cells (Fig. 3f, g).

\section{PAI-1 promotes the migration and invasion of ESCC cells and activates signaling pathways via LRP1}

To clarify whether PAI-1 affects the phenotype and signaling of ESCC cells via LRP1, we suppressed LRP1 mRNA in three TE-series ESCC cells by RNA interference. The silencing of the LRP1 was confirmed using RT-PCR, qRT-PCR, and western blotting (Fig. 4a, $b, c)$. The knockdown of LRP1 in ESCC cells significantly suppressed the rhPAI-1-induced migration and invasion (Fig. 4d, e). The p-Akt and p-Erk1/2 levels decreased following LRP1 knockdown in ESCC cells (Figs. 4f and S5).
PAI-1 induces the migration and invasion of macrophages by activating Akt and Erk1/2 signaling pathways via LRP1

We confirmed the effects of PAI-1 on macrophages by the same methods as above. Coculture with CAF-like cells significantly induced the migration and invasion of macrophages (Fig. 5a, b). Neutralizing antibodies against PAI-1 significantly suppressed the CAF-like cell-induced migration and invasion of macrophages (Fig. 5c, d). We confirmed the expression of LRP1 in macrophages using RTPCR and western blotting (Fig. 5e, f). We found that rhPAI1 significantly promoted the migration and invasion abilities of macrophages (Fig. 5g, H). We observed that rhPAI-1 increased p-Akt and p-Erk1/2 levels in macrophages after 10 min of treatment (Figs. 5i, S6A). However, rhPAI-1 did not affect the M2 polarization of macrophages (Fig. S7). LY294002 and PD98059 suppressed the abilities of migration and invasion in macrophages induced by rhPAI-1 (Fig. 5j, k). We next suppressed LRP1 mRNA in macrophages by RNA interference. LRP1 silencing was confirmed by RT-PCR and western blotting (Fig. 5l, m), and knockdown of LRP1 in macrophages suppressed the rhPAI1-induced migration and invasion (Fig. 5n, o). The levels of PAI-1-induced p-Akt and p-Erk1/2 were also reduced by the knockdown of LRP1 in macrophages (Fig. 5p, S6B).

\section{PAI-1 and LRP1 expression levels correlate with clinicopathological factors and prognosis of patients with ESCC}

To clarify whether expression levels of PAI-1 and LRP1 were significantly associated with clinicopathological factors of patients with ESCC, we performed immunohistochemistry analyses of PAI-1 and LRP1 in 69 human ESCC tissues. We divided the ESCC tissues into high and low expression groups based on the immunoreactivity of PAI-1 in stromal cells and LRP1 in either cancer cells [LRP1 (CA)] or stromal cells [LRP1 (ST)] (Fig. 6a, b, c, d) and confirmed that stromal cells, including CD204 ${ }^{+}$TAMs, expressed LRP1 in human ESCC tissue by double immunofluorescence (Fig. 6e). We found that a high expression level of PAI-1 in the tumor stroma was closely correlated with depth of tumor invasion $(p<0.001)$, high expression levels of $\alpha$ SMA $(p<0.001)$ and FAP $(p<0.001)$, and high numbers of infiltrating $\mathrm{CD} 204^{+}$macrophages $(p=0.002)$ (Table 2). A high expression level of LRP1 (CA) was significantly correlated with a high expression level of FAP $(p=0.031)$ and high numbers of infiltrating $\mathrm{CD} 204^{+}$ macrophages $(p=0.036)$ (Table 2). A high expression level of LRP1 (ST) was significantly correlated with sex $(p=0.031)$, depth of tumor invasion $(p=0.024)$, high 
A

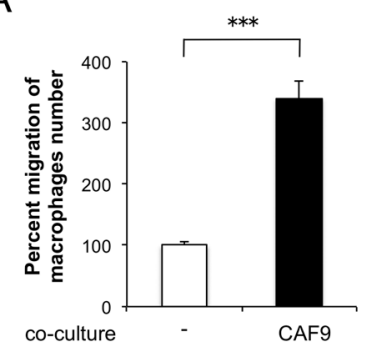

E

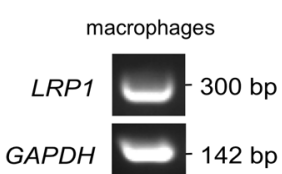

B

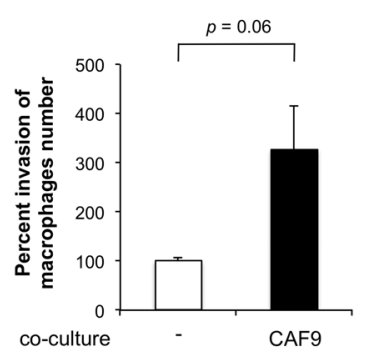

F

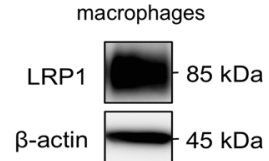

I

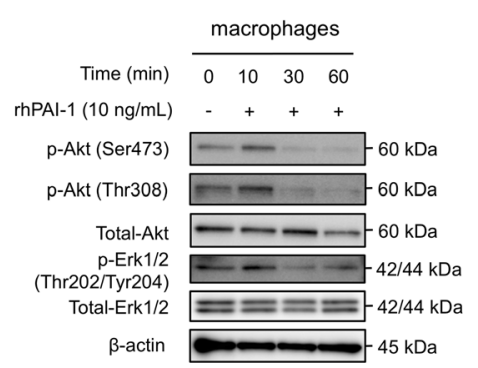

L

M
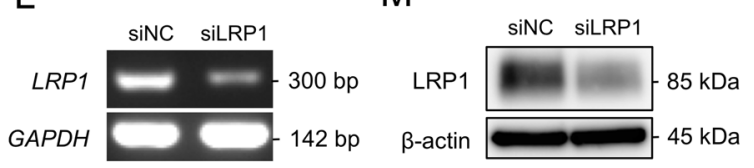

C

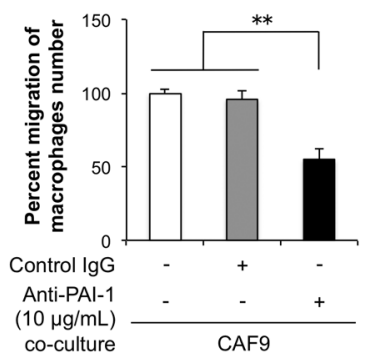

G

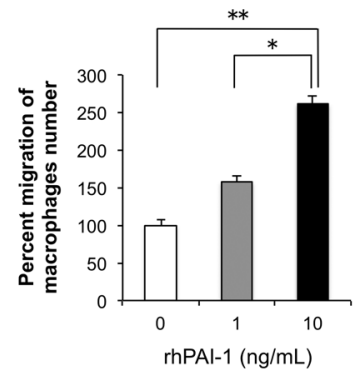

J

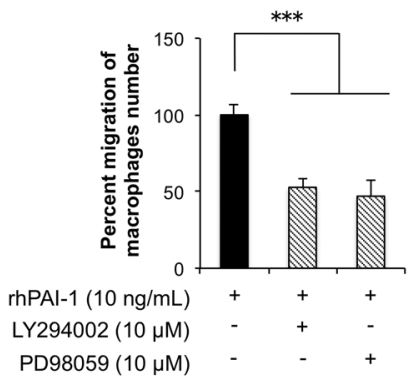

D

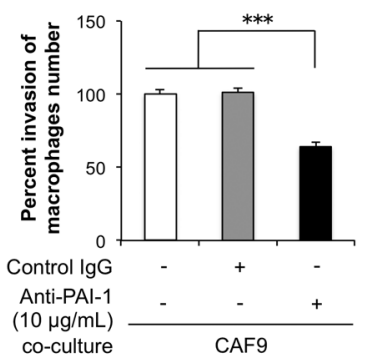

$\mathrm{H}$

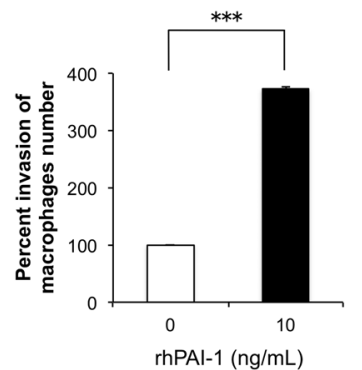

K

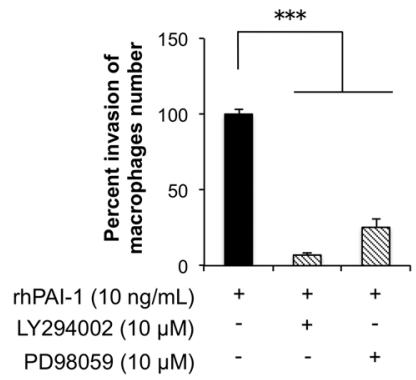

$N$
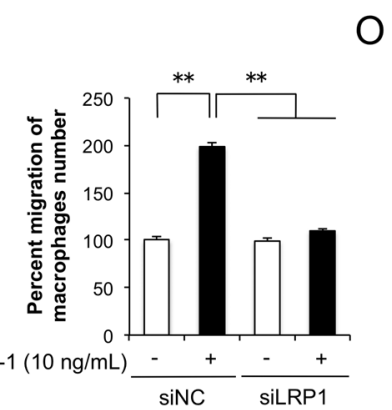

0

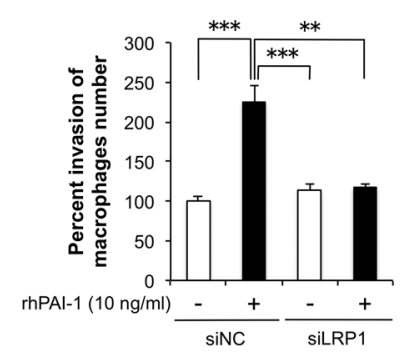

P

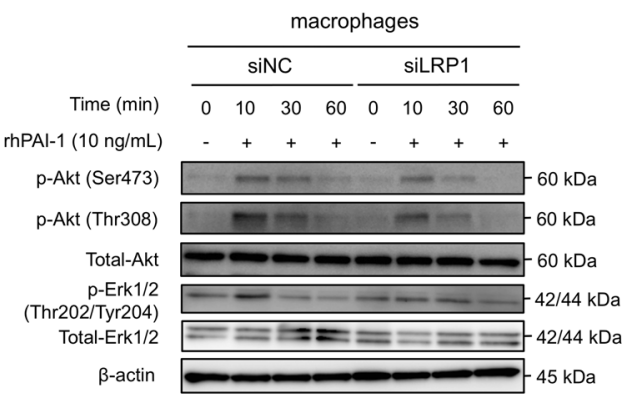

expression levels of $\alpha$ SMA $(p<0.001)$ and FAP $(p=$ 0.001 ), and high numbers of infiltrating $\mathrm{CD} 204^{+}$macrophages $(p=0.001)$ (Table 2).

We next analyzed the prognostic values of PAI- 1 and LRP1 expressions using the follow-up data of the 68 patients with ESCC (one patient could not be followed up after surgery). Kaplan-Meier analysis showed that patients with high expression levels of PAI-1 and LRP1 (ST) had significantly shorter disease-free survival (DFS)
( $p=0.016$ and $p=0.013$, respectively) (Fig. 7a, c), and patients with high expression levels of LRP1 (CA) had significantly shorter CSS $(p=0.041)$ (Fig. 7b). The overall survival of the patients was not significantly affected by PAI-1 $(p=0.246)$, LRP1 (CA) $(p=0.128)$, or LRP1 (ST) $(p=0.288)$ expression. We next divided the patients into three groups based on the combination of PAI-1 and LRP1 (CA) immunoreactivity scores. The patients with high expression levels of both PAI-1 and 
Fig. 5 PAI-1 induces the migration and invasion of macrophages by activating Akt and Erk1/2 signaling pathways via LRP1. a Transwell assay of the effect of CAF9 cell coculturing on the migration of macrophages. b Transwell assay of the effect of CAF9 cell coculturing on the invasion of macrophages. $\mathbf{c}$ Transwell assay of the effect of a PAI-1 neutralizing antibody on the migration of macrophages cocultured with CAF9 cells. Normal goat IgG was used as negative control for the PAI-1 antibody. d Transwell assay of the effect of PAI-1 neutralizing antibody on the invasion of macrophages cocultured with CAF9. Normal goat IgG was used as negative control for the PAI-1 antibody. e The levels of LRP1 mRNA in macrophages by RT-PCR using GAPDH as the control. f The expression level of LRP1 protein in macrophages by western blotting. Anti-LRP1 and $\beta$-actin antibodies were used. $\mathbf{g}$ Transwell assay of the effect of rhPAI1 on the migration of macrophages. $\mathbf{h}$ Transwell assay of the effect of rhPAI-1 on the invasion of macrophages. i Representative western blots of the effect of rhPAI- 1 on the phosphorylation levels of Akt and Erk1/2 in macrophages. Macrophages in serum-free conditions were treated with $10 \mathrm{ng} / \mathrm{mL}$ rhPAI- 1 for $0,10,30$, and $60 \mathrm{~min}$. Western blotting was conducted with total protein extracted from macrophages using specific antibodies against Akt, p-Akt (Ser473), p-Akt (Thr308), Erk1/2, p-Erk1/2 (Thr202/ Tyr204), and $\beta$-actin. j Transwell migration assay of macrophages with or without $10 \mathrm{ng} / \mathrm{mL}$ rhPAI- 1 combined with a PI3K inhibitor (LY294002, $10 \mu \mathrm{M})$ or a MEK1/2 inhibitor (PD98059, $10 \mu \mathrm{M})$. $\mathbf{k}$ Transwell invasion assay of macrophages with or without $10 \mathrm{ng} / \mathrm{mL}$ rhPAI-1 combined with a PI3K inhibitor (LY294002, $10 \mu \mathrm{M}$ ) or a MEK1/2 inhibitor (PD98059, $10 \mu \mathrm{M}$ ). I Macrophages were transfected with $20 \mathrm{nM}$ siRNA targeting $L R P 1$ (siLRP1). siNC was transfected into macrophages as a negative control. LRP1 knockdown was confirmed by RT-PCR using GAPDH as control. m Effective knockdown of LRP1 was confirmed by western blotting using antibodies against LRP1 and $\beta$-actin. $\mathbf{n}$ Transwell assay of the effects of LRP1 knockdown on the migration of macrophages with or without $10 \mathrm{ng} / \mathrm{mL}$ rhPAI- 1 . o Transwell assay of the effects of LRP1 knockdown on the invasion of macrophages with or without $10 \mathrm{ng} / \mathrm{mL}$ rhPAI-1. p Western blotting was performed on the total protein of $L R P 1$-silenced macrophages using specific antibodies against Akt, p-Akt (Ser473), p-Akt (Thr308), Erk1/2, p-Erk1/2 (Thr202/ Tyr204), and $\beta$-actin compared to the control. For (a-d), (g), $(\mathbf{h}),(\mathbf{j}),(\mathbf{k}),(\mathbf{n})$, and $(\mathbf{o})$, migrating and invading cells were counted in four randomly chosen fields, and data represent the mean \pm SEM of triplicate wells for three independent experiments $\left({ }^{*} p<0.05\right.$, ** $p<$ $0.01, * * * p<0.001)$.

LRP1 (CA) had significantly shorter DFS $(p=0.014)$ and CSS $(p=0.008)$ compared to those with low expression levels of both PAI-1 and LRP1 (CA) (Fig. 7d). The patients with high expression levels of either PAI-1 or LRP1 (CA) had significantly shorter DFS $(p=0.018)$ compared to those with low expression levels of both PAI-1 and LRP1 (CA) (Fig. 7d). Similarly, we divided the patients into three groups based on the combination of PAI-1 and LRP1 (ST) immunoreactivity scores. The patients with high expression levels of both PAI-1 and LRP1 (ST) had significantly shorter DFS $(p=0.003)$ and CSS $(p=0.036)$ compared to those with low expression levels of both PAI-1 and LRP1 (ST) (Fig. 7e). In addition, the patients with high expression levels of both PAI-1 and LRP1 (ST) had significantly shorter DFS $(p=0.027)$ compared to those with high expression levels of either PAI-1 or LRP1 (ST) (Fig. 7e).

\section{Discussion}

We previously established an indirect coculture assay in which MSCs cocultured with ESCC cells expressed more FAP than monocultured MSCs [13]. We found that FAP was responsible for the tumor-promoting ability and immunosuppressive phenotype of CAFs. Fibroblast heterogeneity has been recognized, but the absence of CAFspecific markers prevents CAF identification and comparison in different studies [18-20]. Costa et al. characterized four CAF subsets using six fibroblast markers identified in primary CAFs isolated from breast cancer specimens [18]. Only the CAF-S1 subset expressed FAP, and CAF-S1 fibroblasts promoted an immunosuppressive microenvironment by secreting CXCL12 and recruiting $\mathrm{CD} 4{ }^{+} \mathrm{CD} 25^{+}$ $\mathrm{T}$ cells. In this study, we confirmed high expression levels of FAP (Fig. S2A, B) and CXCL12 (Fig. S2C) by CAF-like cells. This expression pattern indicates that CAF-like cells established by coculture with ESCC cells are similar to CAF-S1 subset in primary CAFs, and suggests that indirect coculture of MSCs and ESCC cells may be useful for study the tumor-promoting characteristics of CAFs in an ESCC microenvironment.

In this study, we focused on SERPINE1, one of the upregulated genes in CAF-like cells. PAI-1, encoded by SERPINE1, is a member of the serpin superfamily and is an essential inhibitor of tissue plasminogen activator and urokinase-type (uPA), activators of plasminogen; PAI-1 can also bind LRP1, a major endocytic receptor [21, 22]. The role of PAI-1 in thrombosis is generally known, and elevated PAI-1 levels in tumor tissues correlate with poor prognosis in patients with certain cancers (e.g., esophageal cancer, head and neck squamous cell carcinoma, gastric adenocarcinoma, pancreatic ductal adenocarcinoma, and urothelial carcinoma) [23-25]. Our findings identified CAFs as an important source of PAI-1 in the ESCC microenvironment. Similar to our results, conditioned medium from colon cancer cells can enhance SERPINE1 and ACTA2 expression by CAFs [26]. One study reported that treatment with cisplatin induced CAFs to secrete PAI-1, which contributed to tumor growth and chemoresistance of ESCC cells [27]. However, no reports identify the origin of PAI-1 in the ESCC microenvironment or characterize the detailed effects of CAFs-derived PAI-1 on ESCC cells and macrophages.

Here, we confirmed that PAI-1 accelerated the migration and invasion of ESCC cells and macrophages by activating Akt and Erk1/2 signaling pathways in a 


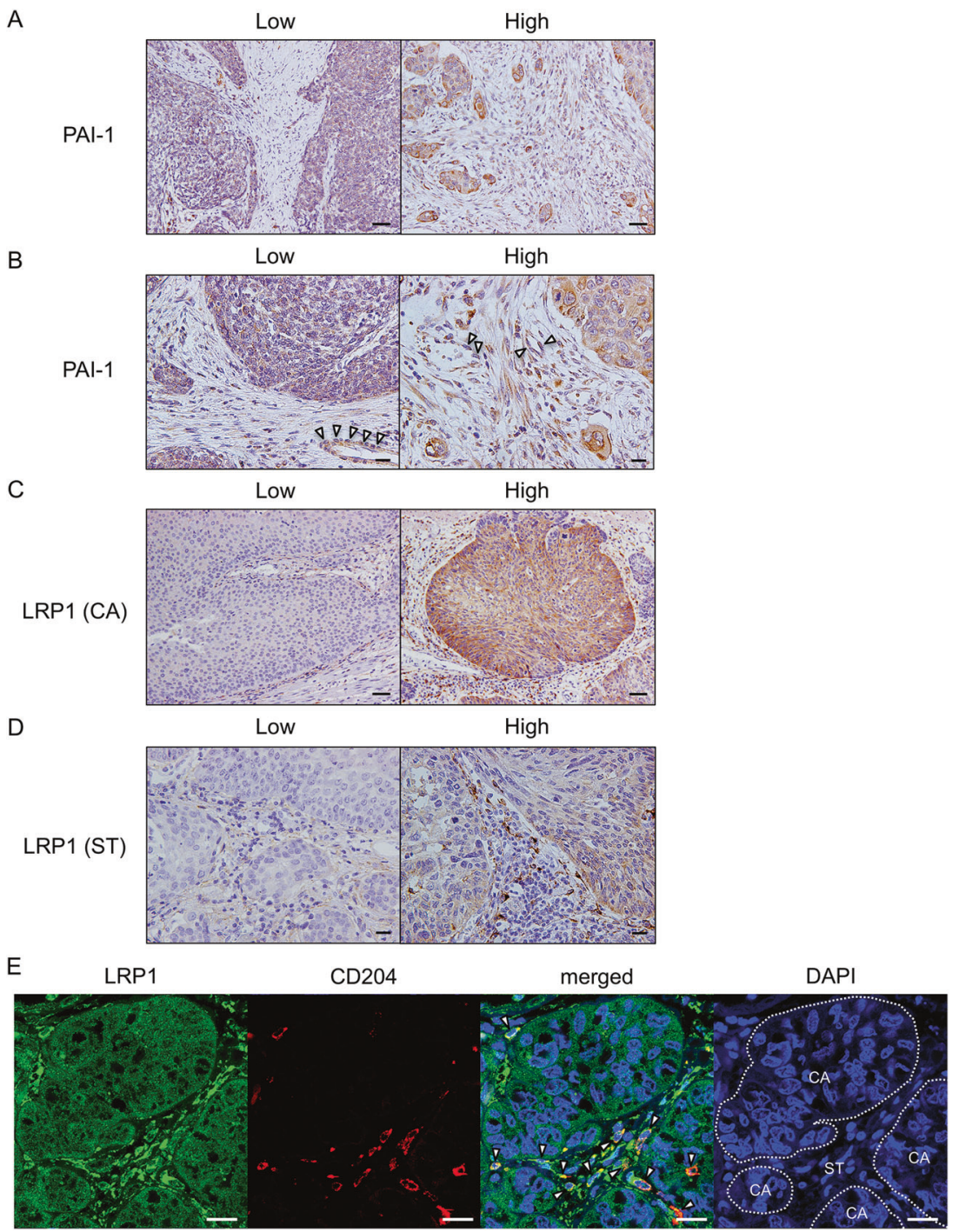

Fig. 6 The expression of PAI-1 and LRP1 in human ESCC tissues. a Immunohistochemical staining for PAI-1 in human ESCC tissues. Representative images are shown: PAI-1 low-intensity in the stroma (left) and PAI-1 high-intensity in the stroma (right). Scale bars $=100$ $\mu \mathrm{m}$. b High-power fields of immunohistochemical staining for PAI-1 in same cases as Fig. 6a. Scale bars $=20 \mu \mathrm{m}$. Arrow heads: vascular endothelial cell. c Immunohistochemical staining for LRP1 in cancer nest of human ESCC tissues. Representative images are shown: LRP1 low-intensity in cancer nest (left) and LRP1 high-intensity in cancer nest (right). Scale bars $=100 \mu \mathrm{m}$. d Immunohistochemical staining for

paracrine manner. Tumor cell-derived PAI-1 enhances the progression of some cancers including ESCC, head and neck cancer, and breast cancer [27-31]. In addition, PAI-1 secreted by non-small cell lung cancer and fibrosarcoma can induce monocyte migration [32]; however, how CAFderived PAI-1 promotes ESCC progression remains unclear. The main findings of this study suggest that PAI1 secreted by CAFs contributes to the migration, invasion, and intracellular signaling of ESCC cells and macrophages in a paracrine manner. Recent in vivo studies have
LRP1 in the stroma of human ESCC tissues. Representative images are shown: LRP1 low-intensity in the stroma (left) and LRP1 highintensity in the stroma (right). Scale bars $=20 \mu \mathrm{m}$. e Stromal cells, including CD204 ${ }^{+}$TAMs, expressed LRP1 in human ESCC tissue. Double immunofluorescence was performed using anti-LRP1 (green) and anti-CD204 (red) antibodies in formalin-fixed paraffin-embedded section of human ESCC tissue. LRP1 was expressed in both cancer cells and stromal cells, and some of the LRP1-positive stromal cells were $\mathrm{CD} 204^{+}$macrophages (arrow heads). Nuclei were stained with DAPI (blue). Scale bar $=20 \mu \mathrm{m}$. CA cancer nest. ST stroma.

noted that PAI-1 inhibitors suppress tumor growth, angiogenesis, and metastasis of some cancers (e.g., ovarian cancer, lung carcinoma, urothelial carcinoma, and fibrosarcoma) [33-36]. These findings suggest that targeting PAI-1 is a potential therapeutic strategy for patients with ESCC.

Our in vitro results suggest that the PAI-1/LRP1 axis is essential to promote the migration and invasion of ESCC cells and macrophages. Several studies have reported that the binding of PAI-1 to LRP1 is involved in the migration, 
Table 2 Expression levels of PAI-1 and LRP1 in human ESCC tissues and their correlation with clinicopathological parameters.

\begin{tabular}{|c|c|c|c|c|c|c|c|c|c|c|}
\hline & \multirow[b]{2}{*}{ Number of cases } & \multicolumn{2}{|c|}{ Expression of PAI- $1^{\mathrm{a}}$} & \multirow[b]{2}{*}{$p$ value } & \multicolumn{2}{|c|}{$\begin{array}{l}\text { Expression of LRP1 } \\
(\mathrm{CA})^{\mathrm{a}}\end{array}$} & \multirow[b]{2}{*}{$p$ value } & \multicolumn{2}{|c|}{$\begin{array}{l}\text { Expression of LRP1 } \\
(\mathrm{ST})^{\mathrm{a}}\end{array}$} & \multirow[b]{2}{*}{$p$ value } \\
\hline & & $\begin{array}{l}\text { Low } \\
(n=42)\end{array}$ & $\begin{array}{l}\text { High } \\
(n=27)\end{array}$ & & $\begin{array}{l}\text { Low } \\
(n=40)\end{array}$ & $\begin{array}{l}\text { High } \\
(n=29)\end{array}$ & & $\begin{array}{l}\text { Low } \\
(n=27)\end{array}$ & $\begin{array}{l}\text { High } \\
(n=42)\end{array}$ & \\
\hline \multicolumn{11}{|l|}{ Age } \\
\hline$<65$ & 32 & 19 & 13 & \multirow[t]{2}{*}{ N.S. } & 17 & 15 & \multirow[t]{2}{*}{ N.S. } & 11 & 21 & \multirow[t]{2}{*}{ N.S. } \\
\hline$\geq 65$ & 37 & 23 & 14 & & 23 & 14 & & 16 & 21 & \\
\hline \multicolumn{11}{|l|}{ Sex } \\
\hline Male & 55 & 34 & 21 & \multirow[t]{2}{*}{ N.S. } & 29 & 26 & \multirow[t]{2}{*}{ N.S. } & 9 & 5 & \multirow[t]{2}{*}{$0.031 *$} \\
\hline Female & 14 & 8 & 6 & & 11 & 3 & & 18 & 37 & \\
\hline \multicolumn{11}{|l|}{ Histological grade ${ }^{\mathrm{b}}$} \\
\hline HGIEN + WDSCC & 15 & 8 & 7 & \multirow[t]{2}{*}{ N.S. } & 10 & 5 & \multirow[t]{2}{*}{ N.S. } & 5 & 10 & \multirow[t]{2}{*}{ N.S. } \\
\hline MDSCC + PDSCC & 54 & 34 & 20 & & 30 & 24 & & 22 & 32 & \\
\hline \multicolumn{11}{|l|}{ Depth of tumor invasion ${ }^{b}$} \\
\hline $\mathrm{T} 1$ & 48 & 37 & 11 & \multirow[t]{2}{*}{$<0.001 * * *$} & 28 & 20 & \multirow[t]{2}{*}{ N.S. } & 23 & 25 & \multirow[t]{2}{*}{$0.024 *$} \\
\hline $\mathrm{T} 2+\mathrm{T} 3$ & 21 & 5 & 16 & & 12 & 9 & & 4 & 17 & \\
\hline \multicolumn{11}{|c|}{ Lymphatic vessel invasion $^{\text {b }}$} \\
\hline Negative & 37 & 26 & 11 & \multirow[t]{2}{*}{ N.S. } & 23 & 14 & N.S. & 17 & 20 & N.S. \\
\hline Positive & 32 & 16 & 16 & & 17 & 15 & & 10 & 22 & \\
\hline Blood vessel invasion ${ }^{\mathrm{b}}$ & & & & & & & & & & \\
\hline Negative & 43 & 27 & 16 & N.S. & 24 & 19 & N.S. & 20 & 23 & N.S. \\
\hline Positive & 26 & 15 & 11 & & 16 & 10 & & 7 & 19 & \\
\hline Lymph node metastasis ${ }^{\mathrm{b}}$ & & & & & & & & & & \\
\hline Negative & 43 & 28 & 15 & N.S. & 25 & 18 & N.S. & 20 & 23 & N.S. \\
\hline Positive & 26 & 14 & 12 & & 15 & 11 & & 7 & 19 & \\
\hline Stage $^{c}$ & & & & & & & & & & \\
\hline $0+\mathrm{I}$ & 38 & 26 & 12 & N.S. & 22 & 16 & N.S. & 18 & 20 & N.S. \\
\hline $\mathrm{II}+\mathrm{III}+\mathrm{IV}$ & 31 & 16 & 15 & & 18 & 13 & & 9 & 22 & \\
\hline Expression of $\alpha \mathrm{SMA}^{\mathrm{d}}$ & & & & & & & & & & \\
\hline Low & 36 & 29 & 7 & $<0.001 * * *$ & 24 & 12 & N.S. & 22 & 14 & $<0.001^{* * *}$ \\
\hline High & 33 & 13 & 20 & & 16 & 17 & & 5 & 28 & \\
\hline Expression of FAP ${ }^{\mathrm{d}}$ & & & & & & & & & & \\
\hline Low & 39 & 31 & 8 & $<0.001 * * *$ & 27 & 12 & $0.031 *$ & 22 & 17 & $0.001 * *$ \\
\hline High & 30 & 11 & 19 & & 13 & 17 & & 5 & 25 & \\
\hline Expression of CD163 & & & & & & & & & & \\
\hline Low & 34 & 23 & 11 & N.S. & 22 & 12 & N.S. & 16 & 18 & N.S. \\
\hline High & 35 & 19 & 16 & & 18 & 17 & & 11 & 24 & \\
\hline Expression of CD204 & & & & & & & & & & \\
\hline Low & 34 & 27 & 7 & $0.002 * *$ & 24 & 10 & $0.036 *$ & 20 & 14 & $0.001 * *$ \\
\hline High & 35 & 15 & 20 & & 16 & 19 & & 7 & 28 & \\
\hline
\end{tabular}

Data were analyzed by $\chi^{2}$-test; $p<0.05$ was considered statistically significant: $* p<0.05 ; * * p<0.01 ; * * * p<0.001$.

${ }^{a}$ The ESCC samples were divided into high and low groups based on the immunoreactivity intensity of PAI-1 in stromal cells or LRP1 in cancer cells (CA) and stromal cells (ST).

${ }^{b}$ According to the Japanese Classification of Esophageal Cancer 10th ed. [47]: HGIEN, high-grade intraepithelial neoplasia; WDSCC, welldifferentiated squamous cell carcinoma; MDSCC, moderately differentiated squamous cell carcinoma; PDSCC, poorly differentiated squamous cell carcinoma. T1a, tumor invades mucosa; T1b, tumor invades submucosa; T2, tumor invades muscularis propria; T3, tumor invades adventitia.

${ }^{\mathrm{c}}$ According to the TNM classification 7th ed. by UICC [48].

${ }^{\mathrm{d}}$ Immunoreactivity around the invasive front of ESCC was divided on the staining area (high: $>30 \%$; low: $\leq 30 \%$ ).

${ }^{\mathrm{e}}$ The median of $\mathrm{CD} 163^{+}$or $\mathrm{CD} 204^{+}$macrophage counts in cancer nests and stroma within the areas were used to divide the patients into low- and high-groups.

invasion, and Akt signaling [21, 23, 29, 32, 37, 38]. PAI-1 can interact with not only LRP1 but also uPA, which binds the uPA plasminogen activator receptor (uPAR). The uPA/ uPAR/PAI-1 system stimulates tumor vascularization by promoting the migration of endothelial cells [23]. However, we confirmed that TE-series ESCC cells did not express uPAR (Fig. S8).

Another group has reported that PAI-1 promotes M2 polarization of monocytes via an IL6/STAT3 autocrine loop in fibrosarcoma [32]; however, we did not observe 
Fig. 7 Correlation of PAI-1 and LRP1 expression in esophageal squamous cell carcinoma (ESCC) tissues with the prognosis of ESCC patients. a Kaplan-Meier analysis of ESCC patients divided into two groups according to PAI-1 expression: PAI-1 Low group $(n=42)$ and PAI-1 High group $(n=26)$. The log-rank test was performed to determine significance $\left({ }^{*} p<0.05\right)$. b Kaplan-Meier analysis of ESCC patients divided into two groups according to LRP1 expression in cancer nest: LRP1 Low group $(n=40)$ and LRP1 High group $(n=28)$. The log-rank test was performed to determine significance $(* p<0.05)$. c Kaplan-Meier analysis of ESCC patients divided into two groups according to LRP1 expression in the stroma: LRP1 Low group $(n=27)$ and LRP1 High group $(n=41)$. The log-rank test was performed to determine significance $(* p<0.05)$.

d Kaplan-Meier analysis of ESCC patients divided into three groups based on the combination of the immunoreactive intensity of PAI-1 in the stroma and LRP1 in cancer nest (CA), as follows: PAI-1 Low/LRP1 (CA) Low $(n=24)$; PAI-1 Low/LRP1 (CA) High and PAI-1 High/LRP1 (CA) Low $(n=34)$; PAI-1 High/LRP1 (CA) High $(n=10)$. The log-rank test was performed to determine significance $(* p<0.05, * * p<$ $0.01)$. e Kaplan-Meier analysis of ESCC patients divided into three groups based on the combination of the immunoreactive intensity of PAI-1 and LRP1 in the stroma (ST), as follows: PAI-1 Low/ LRP1 (ST) Low $(n=21)$; PAI-1 Low/LRP1 (ST) High and PAI-1 High/LRP1 (ST) Low $(n=27)$; PAI-1 High/LRP1 (ST) High $(n=20)$. The log-rank test was performed to determine significance $(* p<0.05$, $* * p<0.01)$. CA, cancer nest. ST, stroma.
A
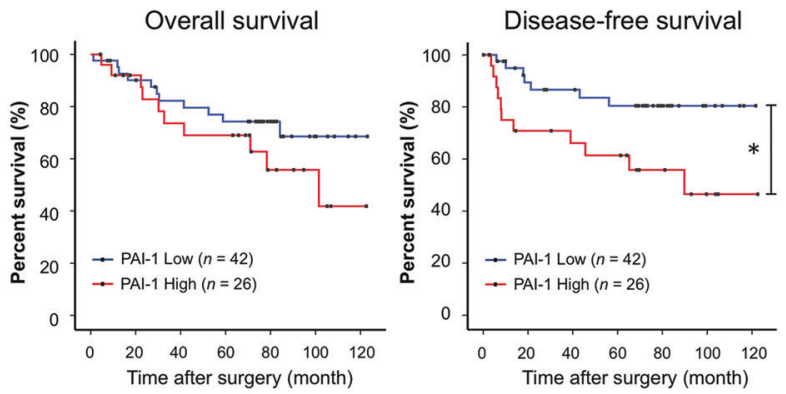

B
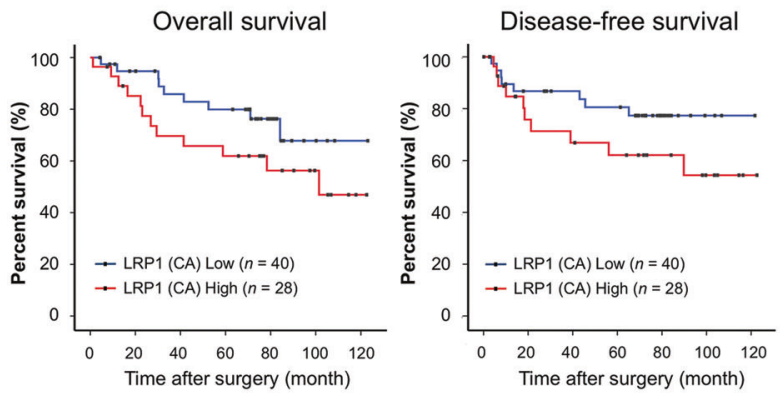

C
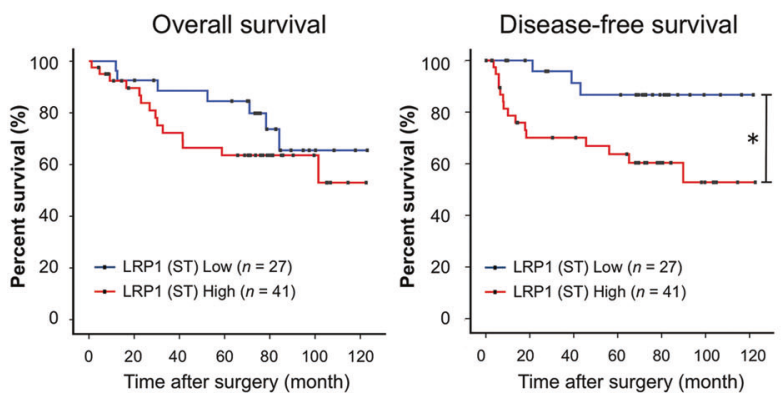

D
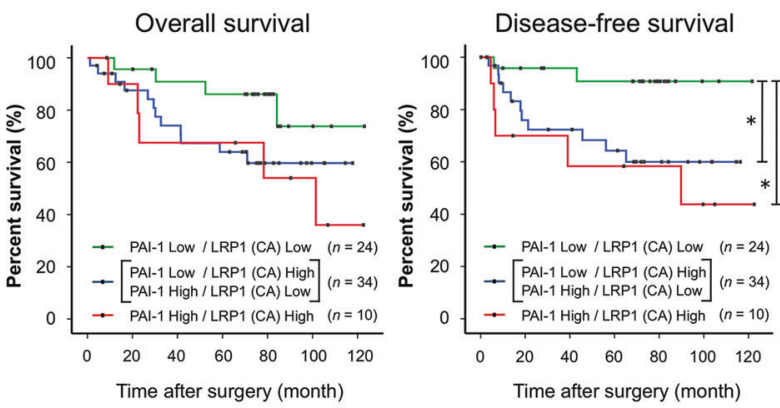

E

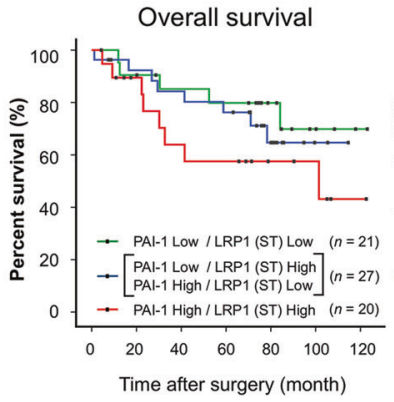

Disease-free survival

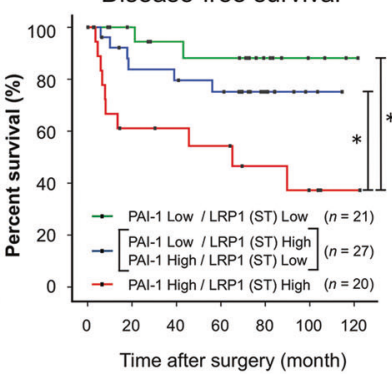

Cause-specific survival

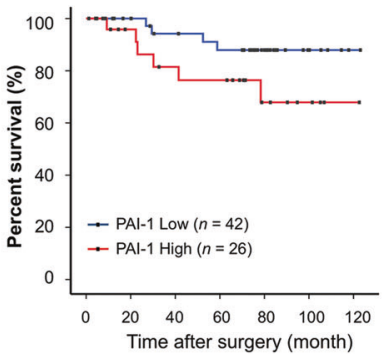

Cause-specific survival

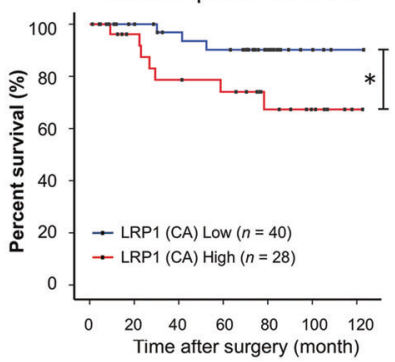

Cause-specific survival

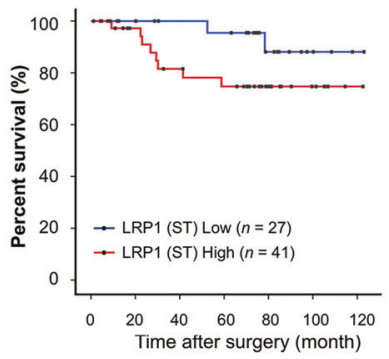

Cause-specific survival

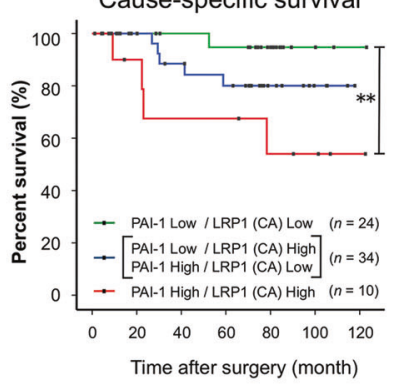

Cause-specific survival

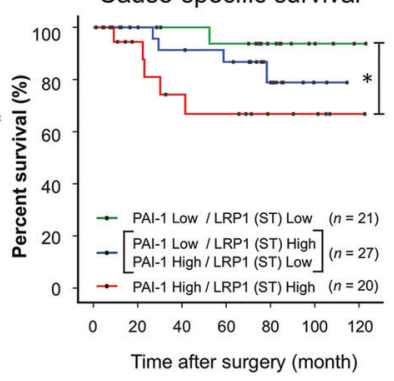

M2 polarization following rhPAI-1 treatment (Fig. S7). This discrepancy may be due to different experimental models; the study above evaluated the effects of PAI- 1 on the shift of PBMos toward the M2 phenotype, while we used PBMos treated with M-CSF, which we defined as macrophages. M-CSF can induce M2 polarization of 
monocytes [39-42]. This may be why rhPAI-1 did not increase the expression of CD163 and CD204 in macrophages in our study. A previous study reported that macrophages expressed LRP1 [37], and in the present study, we confirmed that $\mathrm{CD} 204^{+}$macrophages in human ESCC tissue, TAMs, expressed LRP1 by double immunofluorescence (Fig. 6e), and that the expression level of PAI-1 in stromal cells was associated with high numbers of infiltrating CD204 ${ }^{+}$macrophages. These results indicate that CAF-derived PAI-1 may promote TAM recruitment to ESCC tissue.

Masuda et al. showed that stromal cells express higher levels of PAI-1 than cancer cells in lung adenocarcinoma tissues and that PAI-1 expression correlated with $\alpha \mathrm{SMA}$ levels and depth of tumor invasion [43]. These findings are consistent with our results. Recent studies suggest that elevated PAI-1 and LRP1 expression are indicators of poor prognosis for patients with various cancers [23-25, 33, 38, 44, 45]; however, few studies have distinguished between the expression levels of PAI-1 by cancer nests and tumor stroma [27, 46]. Consistent with our findings, increased expression of PAI-1 by the tumor stroma correlates with poor prognosis in ESCC [27] and breast cancer patients [46], but no reports have evaluated the immunohistochemical expression intensity of both PAI-1 and LRP1 in tumor tissues. Our data demonstrate that ESCC patients with concurrently high expression of PAI-1 by stromal cells and of LRP1 by either cancer cells or stromal cells including TAMs, or both have the shortest survival duration. This finding may support our in vitro results that identify the contribution of the PAI-1/LRP1 axis in ESCC progression.

In conclusion, we demonstrated that PAI-1 derived from CAFs promoted the migration and invasion of both ESCC cells and macrophages via phosphorylation of Akt and Erk1/2 through interaction with LRP1. PAI-1 in CAFs is a potential prognostic factor for patients with ESCC. Targeting the PAI-1/LRP1 axis might, therefore, be a therapeutic approach for ESCC.

Acknowledgements This work was supported by Grants-in-Aid for Scientific Research (17K08693 and 18K07015) from the Japan Society for the Promotion of Science. We thank Maiko Takahashi (Kamakura Techno-Science, Inc.) for her invaluable assistance with the 3D-Gene analysis. We also thank Atsuko Kawashima, Yumi Hashimoto, Nobuo Kubo, and Miki Yamazaki for their excellent technical assistance. We would like to thank Editage for English language editing.

\section{Compliance with ethical standards}

Conflict of interest The authors declare that they have no conflict of interest.

Publisher's note Springer Nature remains neutral with regard to jurisdictional claims in published maps and institutional affiliations.
Open Access This article is licensed under a Creative Commons Attribution 4.0 International License, which permits use, sharing, adaptation, distribution and reproduction in any medium or format, as long as you give appropriate credit to the original author(s) and the source, provide a link to the Creative Commons license, and indicate if changes were made. The images or other third party material in this article are included in the article's Creative Commons license, unless indicated otherwise in a credit line to the material. If material is not included in the article's Creative Commons license and your intended use is not permitted by statutory regulation or exceeds the permitted use, you will need to obtain permission directly from the copyright holder. To view a copy of this license, visit http://creativecommons. org/licenses/by/4.0/.

\section{References}

1. Huang FL, Yu SJ. Esophageal cancer: risk factors, genetic association, and treatment. Asian J Surg. 2018;41:210-5.

2. Pickens A, Orringer MB. Geographical distribution and racial disparity in esophageal cancer. Ann Thorac Surg. 2003;76: S1367-1369.

3. Short MW, Burgers KG, Fry VT. Esophageal cancer. Am Fam Phys. 2017;95:22-28.

4. Wu T, Dai Y. Tumor microenvironment and therapeutic response. Cancer Lett. 2017;387:61-68.

5. Kalluri R. The biology and function of fibroblasts in cancer. Nat Rev Cancer. 2016;16:582-98.

6. Nair N, Calle AS, Zahra MH, Prieto-Vila M, Oo AKK, Hurley L, et al. A cancer stem cell model as the point of origin of cancerassociated fibroblasts in tumor microenvironment. Sci Rep. 2017; 7:6838.

7. Shiga K, Hara M, Nagasaki T, Sato T, Takahashi H, Takeyama H. Cancer-associated fibroblasts: their characteristics and their roles in tumor growth. Cancers. 2015;7:2443-58.

8. Buchsbaum RJ, Oh SY. Breast cancer-associated fibroblasts: where we are and where we need to go. Cancers. 2016;8:19.

9. Herrera M, Herrera A, Dominguez G, Silva J, Garcia V, Garcia $\mathrm{JM}$, et al. Cancer-associated fibroblast and M2 macrophage markers together predict outcome in colorectal cancer patients. Cancer Sci. 2013;104:437-44.

10. Paulsson J, Micke P. Prognostic relevance of cancer-associated fibroblasts in human cancer. Semin Cancer Biol. 2014;25:61-68.

11. Hashimoto O, Yoshida M, Koma YI, Yanai T, Hasegawa D, Kosaka Y, et al. Collaboration of cancer-associated fibroblasts and tumour-associated macrophages for neuroblastoma development. J Pathol. 2016;240:211-23.

12. Yokozaki H, Koma YI, Shigeoka M, Nishio M. Cancer as a tissue: the significance of cancer-stromal interactions in the development, morphogenesis and progression of human upper digestive tract cancer. Pathol Int. 2018;68:334-52.

13. Higashino N, Koma YI, Hosono M, Takase N, Okamoto M, Kodaira $\mathrm{H}$, et al. Fibroblast activation protein-positive fibroblasts promote tumor progression through secretion of CCL2 and interleukin-6 in esophageal squamous cell carcinoma. Lab Invest. 2019;99:777-92.

14. Nishihira T, Hashimoto $Y$, Katayama M, Mori S, Kuroki T, Molecular and cellular features of esophageal cancer cells. J Cancer Res Clin Oncol. 1993;119:441-9.

15. Hosono M, Koma YI, Takase N, Urakawa N, Higashino N, Suemune K, et al. CXCL8 derived from tumor-associated macrophages and esophageal squamous cell carcinomas contributes to tumor progression by promoting migration and invasion of cancer cells. Oncotarget. 2017;8:106071-88.

16. Takase N, Koma YI, Urakawa N, Nishio M, Arai N, Akiyama H, et al. NCAM- and FGF-2-mediated FGFR1 signaling in the tumor 
microenvironment of esophageal cancer regulates the survival and migration of tumor-associated macrophages and cancer cells. Cancer Lett. 2016;380:47-58.

17. Shigeoka M, Urakawa N, Nakamura T, Nishio M, Watajima T, Kuroda D, et al. Tumor associated macrophage expressing CD204 is associated with tumor aggressiveness of esophageal squamous cell carcinoma. Cancer Sci. 2013;104:1112-9.

18. Costa A, Kieffer Y, Scholer-Dahirel A, Pelon F, Bourachot B, Cardon M, et al. Fibroblast heterogeneity and immunosuppressive environment in human breast cancer. Cancer Cell. 2018;33:463-79.

19. Ohlund D, Elyada E, Tuveson D. Fibroblast heterogeneity in the cancer wound. J Exp Med. 2014;211:1503-23.

20. Neuzillet C, Tijeras-Raballand A, Ragulan C, Cros J, Patil Y, Martinet $\mathrm{M}$, et al. Inter- and intra-tumoural heterogeneity in cancer-associated fibroblasts of human pancreatic ductal adenocarcinoma. J Pathol. 2019;248:51-65.

21. Placencio VR, DeClerck YA. Plasminogen activator inhibitor-1 in cancer: rationale and insight for future therapeutic testing. Cancer Res. 2015;75:2969-74.

22. Wang Z, Mottonen J, Goldsmith EJ. Kinetically controlled folding of the serpin plasminogen activator inhibitor 1. Biochemistry. 1996;35:16443-8.

23. Li S, Wei X, He J, Tian X, Yuan S, Sun L. Plasminogen activator inhibitor-1 in cancer research. Biomed Pharmacother. 2018;105:83-94.

24. Liu WJ, Zhou L, Liang ZY, Zhou WX, You L, Zhang TP, et al. Plasminogen activator inhibitor 1 as a poor prognostic indicator in resectable pancreatic ductal adenocarcinoma. Chin Med J. 2018; 131:2947-52.

25. Chan OTM, Furuya H, Pagano I, Shimizu Y, Hokutan K, Dyrskjot $\mathrm{L}$, et al. Association of MMP-2, RB and PAI-1 with decreased recurrence-free survival and overall survival in bladder cancer patients. Oncotarget. 2017;8:99707-21.

26. Hawinkels LJ, Paauwe M, Verspaget HW, Wiercinska E, van der Zon JM, van der Ploeg K, et al. Interaction with colon cancer cells hyperactivates TGF-beta signaling in cancer-associated fibroblasts. Oncogene. 2014;33:97-107.

27. Che Y, Wang J, Li Y, Lu Z, Huang J, Sun S, et al. Cisplatin-activated PAI-1 secretion in the cancer-associated fibroblasts with paracrine effects promoting esophageal squamous cell carcinoma progression and causing chemoresistance. Cell Death Dis. 2018;9:759.

28. Pavon MA, Arroyo-Solera I, Tellez-Gabriel M, Leon X, Viros D, Lopez M, et al. Enhanced cell migration and apoptosis resistance may underlie the association between high SERPINE1 expression and poor outcome in head and neck carcinoma patients. Oncotarget. 2015;6:29016-33.

29. Wei X, Li S, He J, Du H, Liu Y, Yu W, et al. Tumor-secreted PAI-1 promotes breast cancer metastasis via the induction of adipocytederived collagen remodeling. Cell Commun Signal. 2019;17:58.

30. Daubriac J, Han S, Grahovac J, Smith E, Hosein A, Buchanan M, et al. The crosstalk between breast carcinoma-associated fibroblasts and cancer cells promotes RhoA-dependent invasion via IGF-1 and PAI-1. Oncotarget. 2018;9:10375-87.

31. Fortenberry YM, Brandal SM, Carpentier G, Hemani M, Pathak AP. Intracellular expression of PAI-1 specific aptamers alters breast cancer cell migration, invasion and angiogenesis. PLoS One. 2016; 11:e0164288.

32. Kubala MH, Punj V, Placencio-Hickok VR, Fang H, Fernandez GE, Sposto R, et al. Plasminogen activator inhibitor-1 promotes the recruitment and polarization of macrophages in cancer. Cell Rep. 2018;25:2177-91.

33. Nakatsuka E, Sawada K, Nakamura K, Yoshimura A, Kinose Y, Kodama M, et al. Plasminogen activator inhibitor-1 is an independent prognostic factor of ovarian cancer and IMD-4482, a novel plasminogen activator inhibitor-1 inhibitor, inhibits ovarian cancer peritoneal dissemination. Oncotarget. 2017;8:89887-902.

34. Masuda T, Hattori N, Senoo T, Akita S, Ishikawa N, Fujitaka K, et al. SK-216, an inhibitor of plasminogen activator inhibitor-1, limits tumor progression and angiogenesis. Mol Cancer Ther. 2013;12:2378-88.

35. Gomes-Giacoia E, Miyake M, Goodison S, Rosser CJ. Targeting plasminogen activator inhibitor-1 inhibits angiogenesis and tumor growth in a human cancer xenograft model. Mol Cancer Ther. 2013;12:2697-708.

36. Placencio VR, Ichimura A, Miyata $T$, DeClerck YA. Small molecule inhibitors of plasminogen activator inhibitor-1 elicit anti-tumorigenic and anti-angiogenic activity. PLoS One. 2015; 10:e0133786.

37. Cao C, Lawrence DA, Li Y, Von Arnim CA, Herz J, Su EJ, et al. Endocytic receptor LRP together with PAA and PAI-1 coordinates Mac-1-dependent macrophage migration. EMBO J. 2006;25: 1860-70.

38. Roy A, Coum A, Marinescu VD, Polajeva J, Smits A, Nelander S, et al. Glioma-derived plasminogen activator inhibitor-1 (PAI-1) regulates the recruitment of LRP1 positive mast cells. Oncotarget. 2015;6:23647-61.

39. Komohara Y, Ohnishi K, Kuratsu J, Takeya M. Possible involvement of the M2 anti-inflammatory macrophage phenotype in growth of human gliomas. J Pathol. 2008;216:15-24.

40. Duluc D, Delneste Y, Tan F, Moles MP, Grimaud L, Lenoir J, et al. Tumor-associated leukemia inhibitory factor and IL-6 skew monocyte differentiation into tumor-associated macrophage-like cells. Blood. 2007;110:4319-30.

41. Pollard JW. Tumour-educated macrophages promote tumour progression and metastasis. Nat Rev Cancer. 2004;4:71-78.

42. Takaishi K, Komohara Y, Tashiro H, Ohtake H, Nakagawa T, Katabuchi H, et al. Involvement of M2-polarized macrophages in the ascites from advanced epithelial ovarian carcinoma in tumor progression via Stat3 activation. Cancer Sci. 2010;101:2128-36.

43. Masuda T, Nakashima T, Namba M, Yamaguchi K, Sakamoto S, Horimasu $\mathrm{Y}$, et al. Inhibition of PAI-1 limits chemotherapy resistance in lung cancer through suppressing myofibroblast characteristics of cancer-associated fibroblasts. J Cell Mol Med. 2019;23:2984-94.

44. Zhang Y, Zhang YL, Chen HM, Pu HW, Ma WJ, Li XM, et al. Expression of Bmi-1 and PAI-1 in esophageal squamous cell carcinoma. World J Gastroenterol. 2014;20:5533-9.

45. Boulagnon-Rombi C, Schneider C, Leandri C, Jeanne A, Grybek $\mathrm{V}$, Bressenot AM, et al. LRP1 expression in colon cancer predicts clinical outcome. Oncotarget. 2018;9:8849-69.

46. Singer CF, Filipits M, Jahn SW, Abete L, Jakesz R, Greil R, et al. Stromal coexpression of $\mathrm{UPA} / \mathrm{PAI}-1$ protein predicts poor disease outcome in endocrine-treated postmenopausal patients with receptor-positive early breast cancer. Breast. 2019;46:101-7.

47. Japan Esophageal Society. Japanese classification of esophageal cancer, 11th edition: part I. Esophagus. 2017;14:1-36.

48. TNM Classification of Malignant Tumours. 7th Edition. Hoboken, NJ: Wiley-Blackwell; 2011 p. 66-72. 